\title{
Estimates of global terrestrial isoprene emissions using MEGAN (Model of Emissions of Gases and Aerosols from Nature)
}

\author{
A. Guenther ${ }^{1}$, T. Karl ${ }^{1}$, P. Harley ${ }^{1}$, C. Wiedinmyer ${ }^{1}$, P. I. Palmer ${ }^{2}$, and C. Geron ${ }^{3}$ \\ ${ }^{1}$ Atmospheric Chemistry Division, National Center for Atmospheric Research, 1850 Table Mesa Drive, Boulder Colorado, \\ 80305, USA \\ ${ }^{2}$ School of Earth and Environment, University of Leeds, Leeds, LS2 9JT, UK \\ ${ }^{3}$ National Risk Management Research Laboratory, U.S. Environmental Protection Agency, 109 TW Alexander Dr., Research \\ Triangle Park, NC, 27711, USA
}

Received: 16 November 2005 - Published in Atmos. Chem. Phys. Discuss.: 3 January 2006

Revised: 2 June 2006 - Accepted: 29 June 2006 - Published: 2 August 2006

\begin{abstract}
Reactive gases and aerosols are produced by terrestrial ecosystems, processed within plant canopies, and can then be emitted into the above-canopy atmosphere. Estimates of the above-canopy fluxes are needed for quantitative earth system studies and assessments of past, present and future air quality and climate. The Model of Emissions of Gases and Aerosols from Nature (MEGAN) is described and used to quantify net terrestrial biosphere emission of isoprene into the atmosphere. MEGAN is designed for both global and regional emission modeling and has global coverage with $\sim 1 \mathrm{~km}^{2}$ spatial resolution. Field and laboratory investigations of the processes controlling isoprene emission are described and data available for model development and evaluation are summarized. The factors controlling isoprene emissions include biological, physical and chemical driving variables. MEGAN driving variables are derived from models and satellite and ground observations. Tropical broadleaf trees contribute almost half of the estimated global annual isoprene emission due to their relatively high emission factors and because they are often exposed to conditions that are conducive for isoprene emission. The remaining flux is primarily from shrubs which have a widespread distribution. The annual global isoprene emission estimated with MEGAN ranges from about 500 to $750 \mathrm{Tg}$ isoprene (440 to $660 \mathrm{Tg}$ carbon) depending on the driving variables which include temperature, solar radiation, Leaf Area Index, and plant functional type. The global annual isoprene emission estimated using the standard driving variables is $\sim 600 \mathrm{Tg}$ isoprene. Differences in driving variables result in emission estimates that differ by more than a factor of three for specific times and locations. It is difficult to evaluate iso-
\end{abstract}

Correspondence to: A. Guenther

(guenther@ucar.edu) prene emission estimates using the concentration distributions simulated using chemistry and transport models, due to the substantial uncertainties in other model components, but at least some global models produce reasonable results when using isoprene emission distributions similar to MEGAN estimates. In addition, comparison with isoprene emissions estimated from satellite formaldehyde observations indicates reasonable agreement. The sensitivity of isoprene emissions to earth system changes (e.g., climate and land-use) demonstrates the potential for large future changes in emissions. Using temperature distributions simulated by global climate models for year 2100, MEGAN estimates that isoprene emissions increase by more than a factor of two. This is considerably greater than previous estimates and additional observations are needed to evaluate and improve the methods used to predict future isoprene emissions.

\section{Introduction}

Chemicals produced by the biosphere include volatile compounds that are emitted into the air where they can have a substantial impact on the chemistry of the atmosphere. These biogenic gases are dominated by volatile organic compounds (VOCs) both in total mass and number of compounds. The impact of biogenic VOCs on global chemistry and climate has been investigated using global models (e.g., Houweling et al., 1998; Guenther et al., 1999a; Granier et al., 2000; Poisson et al., 2000; Collins et al., 2002; Sanderson et al., 2003) while regional air quality models have included biogenic VOC emissions in efforts to develop pollution control strategies (e.g., Pierce et al., 1998). Biogenic VOC emissions were included as inputs to regulatory regional oxidant

Published by Copernicus GmbH on behalf of the European Geosciences Union. 
models in the mid 1980s (Pierce and Waldruff, 1991) and by the 1990s were routinely included in chemical transport models, but typically as off-line, static emission inventories. There is increasing demand for biogenic emission algorithms that can be integrated into regional and global models. This facilitates studies of earth system interactions and feedbacks and ensures consistency between landcover and weather variables used for atmospheric and land surface process models.

Although hundreds of biogenic VOC have been identified, two compounds dominate the annual global flux to the atmosphere: methane and isoprene. Biogenic methane emissions have primarily been associated with microbial sources, although Keppler et al. (2006) have recently proposed that living foliage is a major source of atmospheric methane. In contrast, terrestrial plant foliage is thought to be the source of $>90 \%$ of atmospheric isoprene. Minor sources of isoprene include microbes, animals (including humans) and aquatic organisms (Wagner et al., 1999). Methane and isoprene each comprise about a third of the annual global VOC emission from all natural and anthropogenic sources. The remaining third is the sum of hundreds of compounds. Methane is a long-lived (years) compound with a relatively well mixed distribution throughout the atmosphere while isoprene is short-lived (minutes to hours) with atmospheric concentrations that vary several orders of magnitude over a time scale of less than one day and over spatial scales of less than a few $\mathrm{km}$. As a result, we can be relatively certain of the annual global emission of methane, based on estimates of the global atmospheric burden and the average lifetime; however, the annual global isoprene emission is much less well constrained. Satellite-derived global distributions of isoprene oxidation products (e.g., formaldehyde and carbon monoxide) are beginning to provide constraints on global isoprene emission rates but they too are associated with significant uncertainties and they cannot provide estimates of past (presatellite era) and future emissions. There remains a need for models that can estimate past, current and future isoprene emissions.

In the early 1990s, the International Global Atmospheric Chemistry (IGAC) Global Emissions Inventory Activity (GEIA) initiated working groups to develop global emission inventories on a 1 degree by 1 degree grid for use in global chemistry and transport models (Graedel et al., 1993). The IGAC-GEIA natural VOC working group developed a model of emissions of isoprene and other VOC (Guenther et al., 1995). A regional biogenic emission model, the Biogenic Emissions Inventory System or BEIS (Pierce and Waldruff, 1991), was developed in the mid 1980s and replaced by a second generation model, BEIS2 (Pierce et al., 1998), in the mid 1990s. This manuscript describes the Model of Emissions of Gases and Aerosols from Nature (MEGAN) which was developed to replace both the Guenther et al. (1995) global emission model and the BEIS/BEIS2/BEIS3 regional emission models. We focus in this paper on isoprene emissions and will describe MEGAN procedures for simulating emis- sions of other gases and aerosols elsewhere. Field and laboratory investigations of the processes controlling isoprene emission are described in this manuscript and data available for model development and evaluation are summarized. The model procedures are described and predicted emissions and the associated uncertainties are discussed and compared to top down emission estimates. Model simulations of the response of isoprene emissions to earth system changes (e.g., climate, chemistry and landcover) are presented and used to identify major uncertainties. Other aspects of isoprene emission (e.g., biological roles, influence on atmospheric chemistry) have been described elsewhere (e.g., Fuentes et al., 2000).

\section{Isoprene observations}

Enclosure methods were first used to study biogenic VOC emissions in the late 1920s (Isidorov, 1990). In the following 75 years, investigators enclosed thousands of leaves, branches and whole plants in bags, jars, and cuvettes to characterize fluxes of isoprene and other VOCs. The earliest studies focused on monoterpenes (see Went, 1960; Isidorov, 1990) but the co-discovery of abundant emissions of isoprene from some plant species by Rasmussen and Went (1965) in the U.S. and Sanadze (1957) in the former Soviet Union led to considerable interest in emissions of this compound. Wiedinmyer et al. (2004) reviewed the scientific literature describing enclosure measurements of foliar emissions of isoprene and other biogenic VOC (BVOC) and have compiled this information into an online database (see http://bvoc.acd.ucar.edu). The database includes the results of $\sim 140$ studies that have characterized isoprene emissions from hundreds of plant species using enclosure measurement systems.

Rasmussen and Went (1965) extrapolated a few biogenic VOC enclosure observations to the global scale by simply multiplying a typical emission rate by the global area covered by vegetation and the fraction of the year that plants are growing. The resulting annual total (isoprene plus all other non-methane biogenic VOC) flux estimate of $438 \mathrm{Tg}\left(10^{12} \mathrm{~g}\right)$ is about a factor of three lower than the estimate of Guenther et al. (1995). This simple approach can be used to establish an upper bound global isoprene emission estimate. The highest leaf-level isoprene emission rates are $\sim 150 \mu \mathrm{g} \mathrm{g}^{-1} \mathrm{~h}^{-1}$. If all leaves emitted continuously at this rate, the global annual isoprene emission would exceed $25 \mathrm{Gt}\left(10^{15} \mathrm{~g}\right)$. However, the actual global annual isoprene emission is about $2 \%$ of this rate due to environmental conditions that are not optimal for isoprene emission and because not all plants have the ability to emit substantial amounts of isoprene.

Guenther et al. (1995) relied primarily on enclosure measurement studies to assign leaf level isoprene emission factors to 72 global ecosystems. The emission factors for about half of these ecosystems were assigned based on 
observations reported in twenty publications and the remaining ecosystems were assigned default values. Only three of the twenty publications included studies from tropical regions even though the tropics were estimated to contribute $\sim 80 \%$ of global annual isoprene emissions. Furthermore, the emission activity algorithms that describe the response of isoprene to temperature and light were based on investigations of temperate plants growing in temperate weather conditions and had not been evaluated by any measurements in the tropics.

Thousands of isoprene emission rate measurements have been made using enclosure techniques in the decade since the Guenther et al. (1995) model was developed. Many of these enclosure measurements have been incorporated into the isoprene emission factors used for MEGAN. Recent studies have also shown that much of the observed isoprene variability among plant species with significant emission rates (e.g., Quercus, Liquidambar, Nyssa, Populus, Salix, and Robinia species) can be attributed to weather, plant physiology and the location of a leaf within the canopy rather than genetics (Geron et al., 2000). Other studies have characterized how emissions respond to various factors including leaf age (Monson et al., 1994; Petron et al., 2001), nutrient availability (Harley et al., 1994), past weather conditions (Sharkey et al., 2000) and the chemical composition of the atmosphere (Velikova et al., 2005; Rosentiel et al., 2003). Of particular importance for global modeling, many more measurements have been conducted in tropical landscapes (Keller and Lerdau, 1999; Guenther et al., 1999a; Kesselmeier et al., 2000; Klinger et al., 2002; Kuhn et al., 2002; Harley et al., 2004). Accompanying these emission measurements have been efforts to process tree inventory data into a format suitable for characterizing regional isoprene emission distributions.

Enclosure measurements of isoprene emission rates can be extrapolated to the whole canopy scale using canopy environment models. The resulting canopy emission rate estimates are associated with substantial uncertainties due to 1) a limited understanding of chemical sinks and deposition losses within vegetation canopies, 2) artificially disturbed emission rates due to the enclosure, 3) differences between the functioning of individual ecosystem components (e.g. leaves) and the entire ecosystem, and 4) limited sample size within the enclosure (relative to the whole landscape), as well as uncertainties associated with canopy microclimate models themselves. Direct measurements of above canopy fluxes are suitable for characterizing whole canopy fluxes and are fortunately becoming increasingly available to parameterize key global ecosystems. Above canopy isoprene flux measurement systems continue to become more reliable and widespread than in the past. Isoprene fluxes can now be measured routinely using eddy flux techniques such as relaxed eddy accumulation (e.g., Guenther et al., 1996) and eddy covariance (Guenther and Hills, 1998). In addition to these direct flux measurement methods, inverse modeling and gradient approaches use isoprene concentrations obtained from aircraft and tethered balloon sampling platforms to characterize isoprene emissions across spatial scales of tens to hundreds of $\mathrm{km}^{2}$ (e.g., Greenberg et al., 1999). The geographical distribution of the field measurements at $\sim 90$ sites used to assign the isoprene emission factor distributions described in this manuscript is illustrated in Fig. 1. Measurements from more than 80 laboratory studies were also incorporated into the development of the model algorithms and emission factors described in this manuscript. While these studies have greatly improved our ability to simulate regional to global isoprene emissions, it should be recognized that the results continue to be based on a very limited set of observations relative to the large variability that occurs in the earth system.

\section{MEGAN model description}

MEGAN estimates the net emission rate (mg compound $\mathrm{m}^{-2}$ earth surface $\mathrm{h}^{-1}$ ) of isoprene and other trace gases and aerosols from terrestrial ecosystems into the above-canopy atmosphere at a specific location and time as

Emission $=[\varepsilon][\gamma][\rho]$

where $\varepsilon\left(\mathrm{mg} \mathrm{m}^{-2} \mathrm{~h}^{-1}\right)$ is an emission factor which represents the emission of a compound into the canopy at standard conditions, $\gamma$ (normalized ratio) is an emission activity factor that accounts for emission changes due to deviations from standard conditions and $\rho$ (normalized ratio) is a factor that accounts for production and loss within plant canopies. The use of standard conditions enables emission rates observed under various conditions to be incorporated into the model. It does not imply that all field observations should be made at these conditions. The MEGAN canopyscale emission factor differs from most other biogenic emission models which use a leaf-scale emission factor. Although canopy-scale measurements are becoming more available, the MEGAN canopy-scale emission factors are still primarily based on leaf and branch-scale emission measurements that are extrapolated to the canopy-scale using a canopy environment model. The standard conditions for the MEGAN canopy-scale emission factors include a leaf area index, LAI, of 5 and a canopy with $80 \%$ mature, $10 \%$ growing and $10 \%$ old foliage; current environmental conditions including a solar angle (degrees from horizon to sun) of 60 degrees, a photosynthetic photon flux density (PPFD) transmission (ratio of PPFD at the top of the canopy to PPFD at the top of the atmosphere) of 0.6 , air temperature $=303 \mathrm{~K}$, humidity $=14 \mathrm{~g} \mathrm{~kg}^{-1}$, wind speed $=3 \mathrm{~m} \mathrm{~s}^{-1}$ and soil moisture $=0.3 \mathrm{~m}^{3} \mathrm{~m}^{-3}$; average canopy environmental conditions of the past 24 to $240 \mathrm{~h}$ include leaf temperature $=297 \mathrm{~K}$ and PPFD $=200 \mu \mathrm{mol} \mathrm{m}^{-2} \mathrm{~s}^{-1}$ for sun leaves and $50 \mu \mathrm{mol} \mathrm{m}^{-2} \mathrm{~s}^{-1}$ for shade leaves. The factor $\gamma$ is equal to unity at these standard conditions. Note that a solar angle of 60 degrees and a PPFD transmission of 0.6 results in a PPFD of $\sim 1500 \mu \mathrm{mol} \mathrm{m}^{-2} \mathrm{~s}^{-1}$ at the top of 


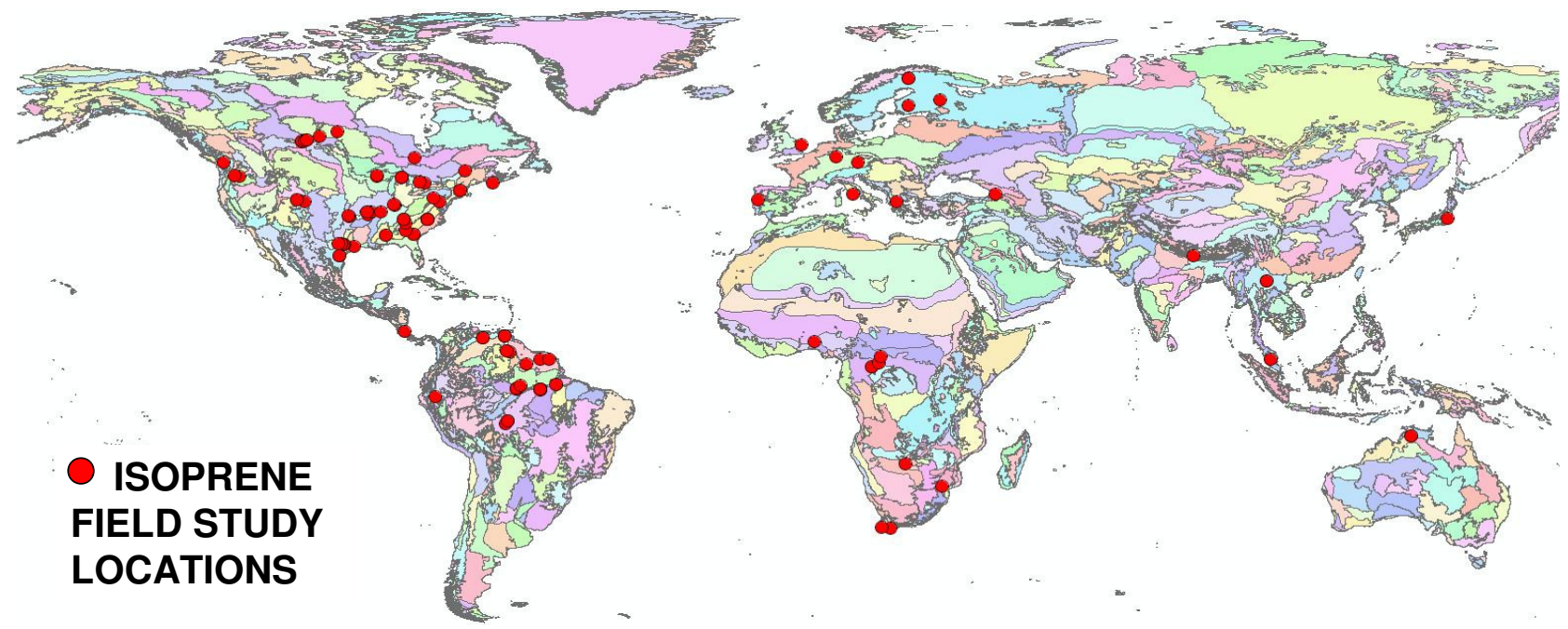

Fig. 1. Geographic distribution of Olson et al. (2001) ecoregions and the locations of isoprene field measurement studies used to develop isoprene emission factors.

the canopy. Emissions are calculated for each plant functional type (PFT) and summed to estimate the total emission for a location. MEGAN is a global scale model with a base resolution of $\sim 1 \mathrm{~km}^{2}$ (30 s latitude by $30 \mathrm{~s}$ longitude) enabling both regional scale and global scale simulations.

The recommended approach for estimating each of the variables in Eq. (1) is application dependent. MEGAN includes a standard method as well as options that provide flexibility for users with limited availability of driving variables or computational resources. The standard approach and available options, and the required driving variables, are summarized in Table 1. The model algorithms and driving variables are described in more detail in the following sections and are available at http://bai.acd.ucar.edu.

\subsection{Emission factor, $\varepsilon$}

Isoprene is emitted by soil bacteria, algae, and in the breath of animals (including humans) as well as plants (Wagner et al. 1999). Only vegetation emissions have been shown to occur at levels that can influence atmospheric composition although relatively little is known about soil bacteria. The isoprene emission rates of different plant species range from $<0.1$ to $>100 \mu \mathrm{g} \mathrm{g}^{-1} \mathrm{~h}^{-1}$. Very low and very high emitters often occur within a given plant family and even within some globally important plant genera including Quercus (oaks), Picea (spruce), Abies (firs) and Acacia. The large taxonomic variability makes the characterization of isoprene emission factor distributions a challenging task.

MEGAN uses an approach that divides the surface of each grid cell into different PFTs and non-vegetated surface. The PFT approach enables the MEGAN canopy environment model to simulate different light and temperature distributions for different canopy types (e.g., broadleaf trees and needle trees). In addition, PFTs can have different LAI and leaf age seasonal patterns (e.g., evergreen and deciduous). MEGAN accounts for regional $\varepsilon$ variations using geographically gridded databases of emission factors for each PFT. For example, the needle evergreen tree isoprene $\varepsilon$ of one grid cell can differ from that of a neighboring location.

Four different emission factor schemes are illustrated in Tables 1 and 2. The number of vegetation types identified in a scheme ranges from one (PFT-1) to unlimited (PFT-REG). Classification schemes with more categories can be collapsed into those with fewer categories. The PFT-REG scheme is used for regional emission modeling simulations. The standard MEGAN global classification scheme, PFT-7, includes seven PFTs: broadleaf evergreen trees, broadleaf deciduous trees, needle evergreen trees, needle deciduous trees, shrubs, crops, and grass plus other ground cover (e.g., sedges, forbs, and mosses). The PFT-1 scheme, designed for simple simulations, has a single isoprene $\varepsilon$ for each location and requires considerably less computational resources and fewer driving variables. The global distribution of the MEGAN PFT-1 emission factor is shown in Fig. 2 with a base resolution of $30 \mathrm{~s}(\sim 1 \mathrm{~km})$. Emission factor hotspots include the southeastern U.S. and southeastern Australia. Figure 2 illustrates the considerable variation in $\varepsilon$ that occurs on both global and regional $(10-100 \mathrm{~km})$ scales. The small scale variability estimated by MEGAN is important for regional modeling simulations due to the short lifetime of isoprene and the non-linear chemistry that determines the impact of isoprene on the chemistry of the atmosphere.

Table 3 illustrates how the global average isoprene emission factors differ between and within PFTs. Broadleaf trees and shrubs have the highest average emission factor. The average needle evergreen tree isoprene emission factor is about 
Table 1. Description of standard method and available options for calculating MEGAN variables in Eqs. (1) and (2).

\begin{tabular}{ll}
\hline Variable & Standard method \\
\hline Emission factor $(\varepsilon)$ & $\begin{array}{l}\text { Use the MEGAN PFT specific } \varepsilon \text { and PFT } \\
\text { cover databases }\end{array}$
\end{tabular}

Canopy environment emission activity factor $\left(\gamma_{\mathrm{CE}}\right)$

Leaf age emission activity factor $\left(\gamma_{\text {age }}\right)$

Soil moisture emission activity factor $\left(\gamma_{S M}\right)$

Canopy loss and production $\left(\rho_{\text {ISO,ISO }}\right)$
The MEGAN canopy environment model is used to estimate hourly leaf-level PPFD and temperature of sun and shade leaves at each canopy depth as function of PFT type, monthly LAI, hourly temperature, solar radiation (including diffuse and PPFD fractions), wind speed, humidity, and soil moisture. Equations (4-9) are then used to estimate $\gamma_{\mathrm{CE}}$ from current and past canopy climate.

Estimate with Eqs. (16-19) as a function of current and previous (within the past 7 to 30 days) LAI and average temperature.

Estimate with Eq. (20) as a function of soil moisture and wilting point

Estimate with Eq. (21) as a function of canopy depth, friction velocity, and chemical lifetime
Alternative methods

1. MEGAN PFT-1 database, with a single $\varepsilon$ for each location.

2. MEGAN PFT-specific $\varepsilon$ with user provided PFT cover distributions. This approach can be used for past and future simulations.

3. PFT-REG database which can be extended with user supplied data.

1. Solar radiation can be estimated from cloud cover. Diffuse and PPFD fractions can be estimated from solar radiation and sun angle.

2. Hourly weather conditions can be estimated from daily minimum and maximum temperature and daily average values of solar radiation, humidity, wind speed, and soil moisture.

3. MEGAN PFT-1 $\varepsilon$ database which requires only one PFT and LAI value for each location.

4. The MEGAN PCEEA algorithm, described by Eqs. (10) through (15), which requires only LAI, solar transmission, and monthly temperature and PPFD.

1. Assume a constant value $\left(\gamma_{\text {age }}=1\right)$.

2. Estimate $\gamma_{\text {age }}$ as a function of LAI using Eq. (16).

3. Use Eq. (16) with user provided estimates of leaf age $\left(F_{\text {mat }}, F_{\text {new }}, F_{\text {gro }}, F_{\text {sen }}\right.$ in Eq. 16$)$.

1. Assume a constant value $\left(\gamma_{S M}=1\right)$.

2. Use $\gamma_{S M}$ distributions provided on MEGAN data portal.

1. Assume a constant value ( $\left.\rho_{\text {ISO,ISO }}=0.96\right)$. a factor of six lower than the average broadleaf tree emission factor. The needle deciduous tree and grass PFTs have average emission factors that are about a factor of 20 lower than the average broadleaf tree emission factor, while the crop isoprene emission factor is about two orders of magnitude lower. The substantial differences in these global average isoprene emission factors demonstrates the value of the PFT7 approach but Table 3 also shows that there is considerable variability associated with the isoprene emission factors assigned to different species within a single PFT. For example, the isoprene emission factor for broadleaf trees ranges from 0.1 to $30 \mathrm{mg} \mathrm{m}^{-2} \mathrm{~h}^{-1}$. Global total isoprene emissions can be approximated using a constant emission factor for each of the seven PFTs but this will introduce significant errors due to correlations between $\varepsilon$ and $\gamma$ distributions. For example, the broadleaf trees that grow in montane and boreal regions often have high isoprene emission factors but low isoprene emission activity factors. Furthermore, there will be substantial errors in estimates for any location where $\varepsilon$ deviates significantly from the PFT average $\varepsilon$. 
Table 2. Examples of plant species assignments for MEGAN PFT classification schemes.

\begin{tabular}{|c|c|c|c|c|c|}
\hline \multirow{2}{*}{$\begin{array}{l}\text { Plant species } \\
\text { Scientific name }\end{array}$} & \multicolumn{5}{|c|}{ Classification schemes } \\
\hline & Common name & PFT-1 & PFT-7 & PFT-CLM & PFT-REG \\
\hline Pinus Ponderosa & Ponderosa Pine & Veg & Needle evergreen Tree & $\begin{array}{l}\text { Needle evergreen } \\
\text { temperate tree }\end{array}$ & Pine tree \\
\hline Larix decidua & European larch & Veg & Needle deciduous tree & $\begin{array}{l}\text { Needle deciduous bo- } \\
\text { real }\end{array}$ & Larch tree \\
\hline Hymenaea courbaril & Jatoba & Veg & Broadleaf evergreen tree & $\begin{array}{l}\text { Broadleaf evergreen } \\
\text { tropical tree }\end{array}$ & $\begin{array}{l}\text { Broadleaf evergreen } \\
\text { tropical tree }\end{array}$ \\
\hline Quercus douglasii & Blue oak & Veg & Broadleaf deciduous tree & $\begin{array}{l}\text { Broadleaf deciduous } \\
\text { temperate tree }\end{array}$ & Deciduous oak tree \\
\hline Larrea tridentata & Creosote bush & Veg & Shrub & $\begin{array}{l}\text { Broadleaf evergreen } \\
\text { shrub }\end{array}$ & Tall desert shrub \\
\hline Juniperus horizontalis & Creeping juniper & Veg & Shrub & Not applicable & $\begin{array}{l}\text { Needle evergreen } \\
\text { shrub }\end{array}$ \\
\hline Pseudoroegneria spicata & Bluebunch wheatgrass & Veg & Grass and other ground cover & C3 non-arctic grass & Bunchgrass \\
\hline Sphagnum capillifolium & Peat moss & Veg & Grass and other ground cover & Not applicable & Moss \\
\hline Zea mays & Corn & Veg & Crop & Corn & Corn \\
\hline Oryza sativa & Rice & Veg & Crop & Not Applicable & Rice \\
\hline
\end{tabular}

Table 3. Global average emission factors, $\varepsilon\left(\mathrm{mg}\right.$ isoprene $\left.\mathrm{m}^{-2} \mathrm{~h}^{-1}\right)$, land area $\left(10^{6} \mathrm{~km}^{2}\right)$ and percent contribution to the annual global and regional isoprene emission associated with major plant functional types. The range of land area estimates is based on the PFT databases described in Table 2.

\begin{tabular}{clllllll}
\hline & & $\begin{array}{l}\text { Broadleaf } \\
\text { Evergreen and } \\
\text { Decid. Trees }\end{array}$ & $\begin{array}{l}\text { Needle } \\
\text { Evergreen } \\
\text { Trees }\end{array}$ & $\begin{array}{l}\text { Needle } \\
\text { Deciduous } \\
\text { Trees }\end{array}$ & Shrubs & Crops & $\begin{array}{l}\text { Grass } \\
\text { and other }\end{array}$ \\
\hline Global $\varepsilon:$ & Average & 12.6 & 2.0 & 0.7 & 10.7 & 0.09 & 0.5 \\
Range & 0.1 to 30 & $0.01-13$ & $0.01-2$ & 0.1 to 30 & 0.01 to 1 & 0.004 to 1.2 \\
Global land area & 13.4 to 38.5 & 8.6 to 20.0 & 1.3 to 3.9 & 15.6 to 24.4 & 8 to 36.5 & 17.2 to 38.6 \\
Emission & Tropical & $45 \%$ & $<0.01 \%$ & $<0.01 \%$ & $28 \%$ & $0.3 \%$ & $0.6 \%$ \\
& Temperate & $4.8 \%$ & $0.3 \%$ & $<0.01 \%$ & $4.5 \%$ & $<0.01 \%$ & $0.3 \%$ \\
& Mediterranean & $0.2 \%$ & $0.1 \%$ & $<0.01 \%$ & $1.5 \%$ & $<0.01 \%$ & $<0.01 \%$ \\
& Boreal/Tundra & $0.3 \%$ & $0.4 \%$ & $<0.01 \%$ & $1.0 \%$ & $<0.01 \%$ & $0.2 \%$ \\
& Arid lands & $0.3 \%$ & $0.1 \%$ & $<0.01 \%$ & $11 \%$ & $<0.01 \%$ & $0.2 \%$ \\
& Global & $51 \%$ & $1.1 \%$ & $<0.01 \%$ & $46 \%$ & $0.3 \%$ & $1.4 \%$ \\
\hline
\end{tabular}

Isoprene emission factor distributions for each PFT were estimated by combining the isoprene observations described in Sect. 2 with landcover information that includes ground measurement inventories, satellite based inventories, and ecoregion descriptions. The available landcover and isoprene observations differ considerably for different PFTs and geographic regions. In some cases, vegetation inventories were combined with satellite observations to generate high resolution (e.g., $30 \mathrm{~m}$ to $1 \mathrm{~km}$ ) species composition distributions, while in other cases general descriptions were used to characterize global ecoregions. A description of these methods is given below.

Since geographical distributions of PFTs and PFT-specific isoprene emission factors change with time, the distributions used to estimate emissions should be representative of the time period being simulated. Climate and land management change can substantially modify species composition and to- tal vegetation cover, and therefore PFT and $\varepsilon$ values, on time scales of weeks to centuries. Emission model investigations of changes in species composition and total vegetation have estimated that significant (10\%) isoprene emission changes can occur on a time scale of 25 years for climate driven changes (Martin and Guenther, 1995), 10 years for land management practices such as overgrazing (Guenther et al., 1999b) and two years for land management practices such as cropland abandonment (Schaab et al., 2000). Other land management practices, such as forest clear-cutting, could result in large changes in isoprene emissions over a period of weeks. These studies show that global PFT and $\varepsilon$ databases are needed on a time scale of $\sim 25$ years for simulating global earth system changes. A considerably shorter time scale, weeks to a decade, may be required for regional studies investigating the impacts of land cover change. 


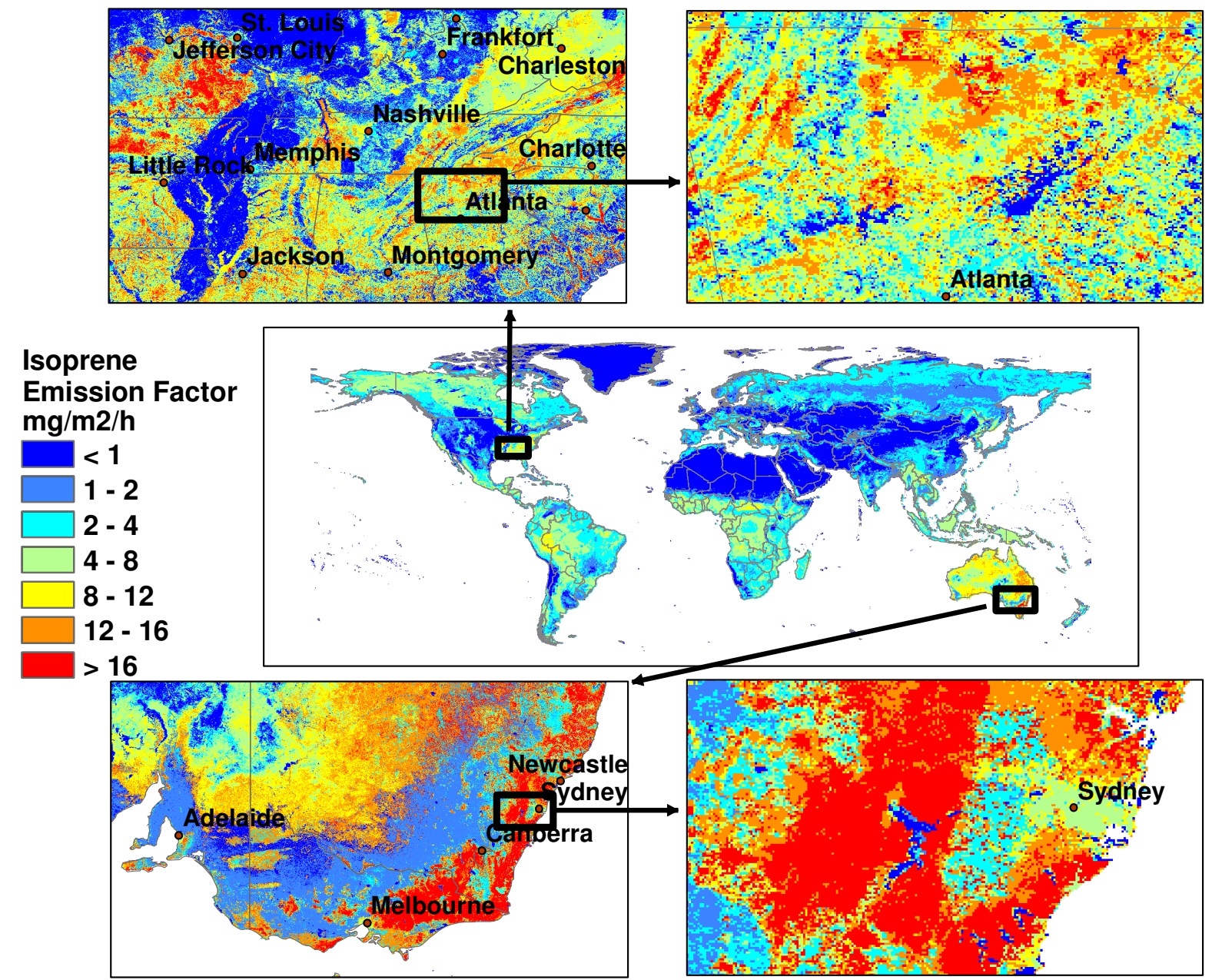

Fig. 2. Global distribution of landscape-average isoprene emission factors $\left(\mathrm{mg}\right.$ isoprene $\left.\mathrm{m}^{-2} \mathrm{~h}^{-1}\right)$. Spatial variability at the base resolution $(\sim 1 \mathrm{~km})$ is shown by regional images of the southeastern U.S. and southeastern Australia.

\subsubsection{Trees}

Trees have been the focus of most isoprene emission rate measurement studies and there is a relatively large database for assigning tree emission factors. Trees are also economically valuable which has led to the compilation of high resolution geographically referenced tree inventories in Eurasia (e.g., France, Germany, United Kingdom, Japan, China, Russia), North America (e.g., U.S., Canada), Africa (south of the equator), Australia and New Zealand. Biogenic emission inventories have been developed using summaries (i.e., county, province, national totals) based on this information (e.g., Geron et al., 1994; Klinger et al., 2002; Otter et al., 2003; and Simpson et al., 1999). MEGAN integrates plot level species composition data, where available, and regional summaries, for other regions, into the MEGAN PFT-REG database which currently covers all or parts of Eurasia, North America, Australia and New Zealand. The MEGAN PFTREG distributions and associated species specific emission factors are used as the basis for weighted average emission factors used with the PFT-CLM, PFT-7, and PFT-1 databases to maintain consistency between regional and global estimates.

For regions without quantitative tree inventories, isoprene emission factors are assigned to the 867 ecoregions in the digital terrestrial ecoregion database developed by Olson et al. (2001) and illustrated in Fig. 1. The assigned $\varepsilon$ are based on ecoregion descriptions of common plant species and available isoprene emissions measurements. A default value, based on the global average for other regions, is assigned if no measurements are available for characterizing trees in the ecoregion. This scheme provides global coverage using an approach that contains sufficient resolution to simulate biogeographical units with similar isoprene emission characteristics. The Olson et al. (2001) database is the product of over 1000 biogeographers, taxonomists, conservation biologists and ecologists from around the world. Most ecoregions include a fairly detailed description of the dominant 


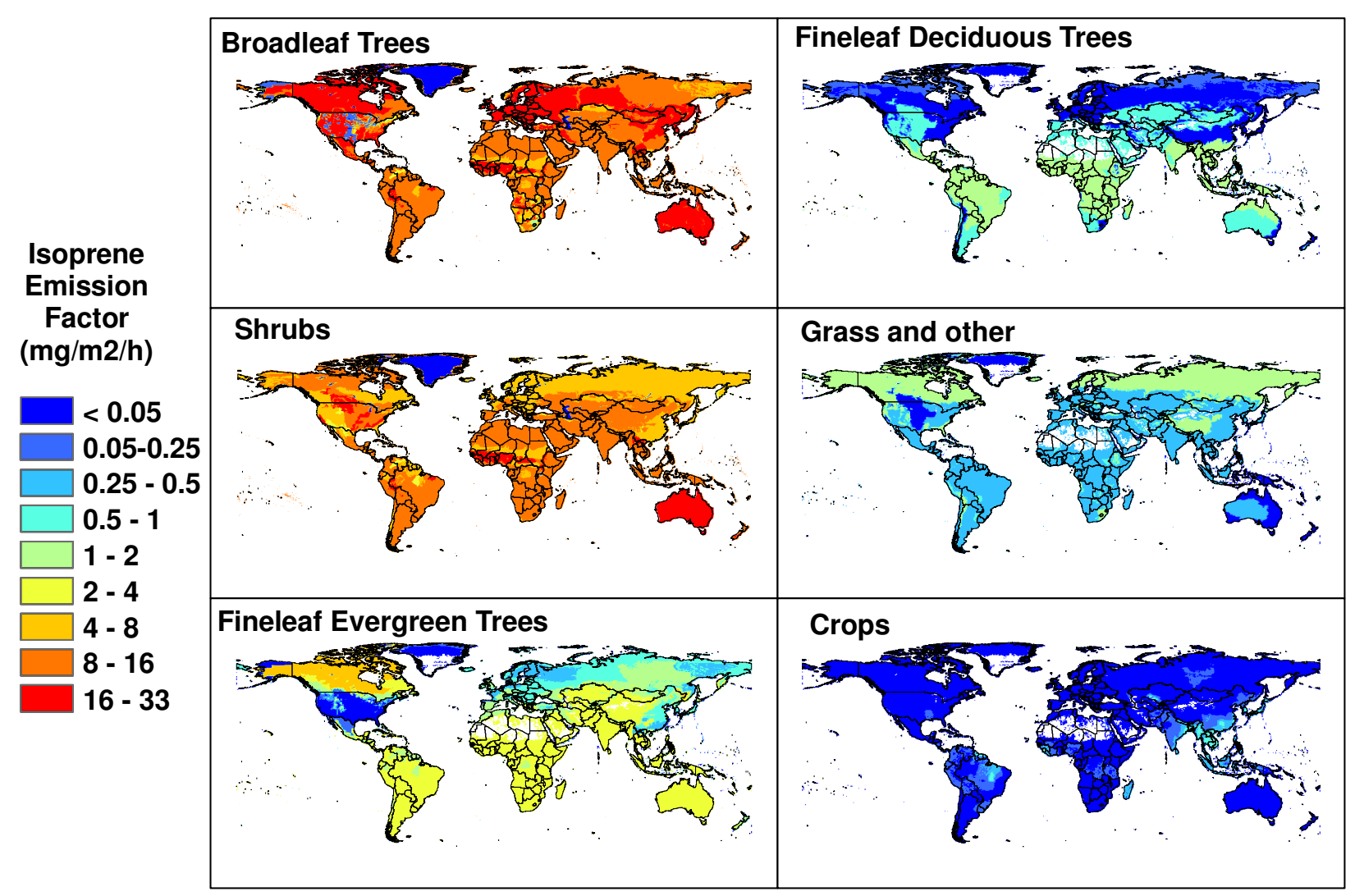

Fig. 3. Global distribution of isoprene emission factors for the MEGAN PFTs.

plant species found within the region. Uncertainties associated with $\varepsilon$ distributions for tropical broadleaf trees are a major component of the overall uncertainty in global isoprene emission estimates. Figure 1 shows that there are other large regions, such as boreal forests and tundra forests of Siberia, with no reported observations. All of the dominant tree genera in Siberia have been sampled in other regions but Siberian tree species could have different emission characteristics. Accurate emission rates for any region are strongly dependent on the availability of accurate emission rate measurements of the regionally dominant species.

Figure 3 illustrates the global distribution of PFT specific isoprene emission factors. Broadleaf tree isoprene emission factors are close to the PFT global average of $12.6 \mathrm{mg} \mathrm{m}^{-2} \mathrm{~h}^{-1}$ in most regions but are $<1 \mathrm{mg} \mathrm{m}^{-2} \mathrm{~h}^{-1}$ and $\sim 20 \mathrm{mg} \mathrm{m}^{-2} \mathrm{~h}^{-1}$ in other regions. Needle evergreen tree $\varepsilon$ range from $>4 \mathrm{mg} \mathrm{m}^{-2} \mathrm{~h}^{-1}$ in Canada to $<0.5$ in the U.S. and Europe. The isoprene emission factors for needle deciduous trees are generally very low since this PFT is dominated by trees, e.g., larch (Larix), that do not emit substantial amounts of isoprene.

\subsubsection{Shrubs, grass and other vegetation}

In comparison with trees, there are relatively few measurements of isoprene emission factors for shrub, grass, and other plant species. In addition, there is less quantitative data on distributions of these plants due to their lesser economic importance. However, some countries (e.g., United States, United Kingdom) have landcover characterization efforts that include shrubs and ground cover and this information is being incorporated into the MEGAN emission factors.

Shrub emission factors are based on available shrub emission measurements and descriptions of shrub species distributions from quantitative ground surveys, in the U.S. only, or estimates based on descriptions of dominant species in each of the 867 Olson ecoregions. The resulting emission factor distribution is illustrated in Fig. 3. The relatively large uncertainty associated with shrub emission factors and the substantial global emission results in a large contribution of shrub isoprene emission to the overall uncertainty in global isoprene emission estimates.

Isoprene emission is rarely observed from plants that are entirely "non-woody". A rare example is the spider-lily, $\mathrm{Hy}$ menocallis americana (Geron et al., 2006). However, there are a number of isoprene-emitting plants that fall within the MEGAN PFT for grass and other vegetation. Some of the 
important isoprene emitting genera in this category include Phragmites (a reed), Carex (a sedge), Stipa (a grass) and Sphagnum (a moss). Reported isoprene emission factors for herbaceous cover range from $\sim 0.004 \mathrm{mg} \mathrm{m}^{-2} \mathrm{~h}^{-1}$ for grasslands in Australia (Kirstine et al., 1998) and central U.S. (Fukui and Doskey, 1998) to $\sim 0.4 \mathrm{mg} \mathrm{m}^{-2} \mathrm{~h}^{-1}$ for a grassland in China (Bai et al., 2006) and $\sim 1.2 \mathrm{mg} \mathrm{m}^{-2} \mathrm{~h}^{-1}$ for forests and wetlands in southern U.S. (Zimmerman, 1979), northern U.S. (Isebrands et al., 1999), Canada (Klinger et al., 1994) and Scandanavia (Janson et al., 1999). One of these three values is assigned to the grass and other vegetation PFT in each of the 867 ecoregions to develop the emission factor distribution shown in Fig. 3.

\subsubsection{Crops}

At least one enclosure measurement has characterized each of the 25 globally dominant crop genera and none have been found to emit isoprene (see http://bvoc.acd.ucar.edu). However, agricultural landscapes are isoprene sources in at least some regions. Plantations of isoprene-emitting trees (e.g., poplar, eucalyptus, oil palms) are major isoprene sources at some locations. In addition, isoprene-emitting plants are introduced into croplands to increase nitrogen availability and to provide windbreaks. Nitrogen fixing plants grown in croplands to provide "green manure" include Velvet bean $(\mathrm{Mu}$ cuna pruriens, a legume) in cornfields and Azolla, an aquatic fern, in rice paddies. Both of these plants produce substantial amounts of isoprene (Silver and Fall, 1995). While the use of Velvet bean is relatively limited, Azolla is widely used in the major rice producing regions (Clark, 1980). Tropical kudzu (Pueraria phaseoloides) is the most widely used "green manure" plant in tropical agricultural lands. Although there are no reported isoprene emission measurements for tropical kudzu, all other examined Pueraria species have been identified as isoprene emitters (e.g., Guenther et al., 1996). We have used the global crop distribution database of Leff et al. (2004) to identify agricultural landscapes (oil palm and rice) where isoprene emissions are likely higher than in other agricultural regions. The elevated isoprene emission associated with oil palm plantations is primarily due to oil palms while rice field isoprene emission is primarily from Azolla, which grows in some but not all rice fields, and not from the rice plants. Additional studies are needed to characterize the distribution of Azolla in rice fields but presently an isoprene $\varepsilon$ of $1 \mathrm{mg} \mathrm{m}^{-2} \mathrm{~h}^{-1}$ is assigned to crop PFT in landscapes dominated by rice fields. An isoprene emission factor of $10 \mathrm{mg} \mathrm{m}^{-2} \mathrm{~h}^{-1}$ is assigned to crop PFT in areas dominated by oil palm plantations and a value of $0.01 \mathrm{mg} \mathrm{m}^{-2} \mathrm{~h}^{-1}$ is assigned to all other regions.

\subsection{Emission activity factor $(\gamma)$}

Experimental evidence over the past two decades has implicated a number of physical and biological factors in modify- ing the capacity of a leaf to emit isoprene. Among these factors are incident PPFD and leaf temperature, which control emissions on short (seconds to minutes) time scales (Guenther et al., 1993), but which also influence the isoprene emission capacity of a leaf over longer (hours to weeks) time scales (Monson et al., 1994; Sharkey et al., 2000; Geron et al., 2000; Petron et al., 2001). A leaf's ability to emit isoprene is clearly influenced by leaf phenology; generally speaking, very young leaves of isoprene-emitting species emit no isoprene, mature leaves emit maximally, and as leaves senesce, emission capacity gradually declines. Although studies indicate that isoprene emission is less sensitive than photosynthesis to decreasing soil moisture (Pegoraro et al., 2004), increasing drought directly effects isoprene emission (as well as indirectly mediating emissions through changes in leaf temperature). Finally, there is growing evidence that changes in the composition of the atmosphere, e.g., increased $\mathrm{CO}_{2}$ (Rosenstiel et al., 2003) and episodic increases in ozone (Velikova et al., 2005), may affect isoprene emission capacity. The available observations of the response of isoprene emission to $\mathrm{CO}_{2}$ and $\mathrm{O}_{3}$ variations are not suitable for developing robust numerical algorithms and so have not been incorporated into the current version of MEGAN.

The emission activity factor describes variations due to the physiological and phenological processes that drive isoprene emission rate changes. The total emission activity factor is the product of a set of non-dimensional emission activity factors that are each equal to unity at standard conditions,

$\gamma=\gamma_{\mathrm{CE}} \cdot \gamma_{\mathrm{age}} \cdot \gamma_{\mathrm{SM}}$

where $\gamma_{\mathrm{CE}}$ describes variation due to LAI and light, temperature, humidity and wind conditions within the canopy environment, $\gamma_{\text {age }}$ makes adjustments for effects of leaf age, and $\gamma_{\mathrm{SM}}$ accounts for direct changes in $\gamma$ due to changes in soil moisture. Descriptions of the methods used to estimate each of the activity factors included in Eq. (2) are given below.

\subsubsection{Canopy environment $\left(\gamma_{\mathrm{CE}}\right)$}

Isoprene emissions are strongly dependent on leaf temperature and PPFD incident on the leaf (Guenther et al., 1993). Incident PPFD and temperature of leaves within a canopy can differ substantially from above canopy conditions but can be estimated for sun and shade leaves in each layer using a canopy environment model. The canopy average influence of leaf PPFD and temperature, $\gamma_{\mathrm{CE}}$, is estimated as

$\gamma_{\mathrm{CE}}=C_{\mathrm{CE}} \cdot \gamma_{\mathrm{PT}} \cdot \mathrm{LAI}$

where $\mathrm{C}_{\mathrm{CE}}(=0.57$ for the MEGAN canopy environment model) is a factor that sets the emission activity to unity at standard conditions, $\gamma_{\mathrm{PT}}$ is the weighted average, for all leaves, of the product of a temperature emission activity factor $\left(\gamma_{T}\right)$ and a PPFD emission activity factor $\left(\gamma_{P}\right)$, and LAI is leaf area index. Note that $\gamma_{P}$ decreases with inceasing LAI. 
Leaves in direct sunlight often experience temperatures that are a degree or more higher than ambient air while shaded leaves are often cooler than ambient air temperature. PPFD can be very low on shaded leaves in dense canopies and the PPFD of sun leaves depends on the angle between the sun and the leaf. Guenther et al. (1995) used a relatively simple canopy environment model to estimate PPFD on sun and shade leaves at several canopy depths and assumed that leaf temperature was equal to air temperature. The non-linear relationships between isoprene emission and environmental conditions, coupled with the strong correlation between PPFD and temperature, will result in a significant underestimation of isoprene emissions if canopy or daily average PPFD and temperature are used (rather than calculating emissions for each canopy level and each hour of the day). Lamb et al. (1996) evaluated the use of several canopy environment models for predicting whole canopy isoprene fluxes and found that the results from both simple and complex canopy models were within the uncertainty range of observed isoprene fluxes. Although detailed canopy environment models may not always substantially improve isoprene emission estimates, these models may be important for investigating how changes in environmental conditions will perturb isoprene emission rates. The integration of MEGAN within the land surface model component of an earth system model will allow investigations of interactions between isoprene emissions and environmental conditions. The standard MEGAN canopy environment model is based on the methods described by Guenther et al. (1999a). This model estimates incident PPFD and temperature of sun and shade leaves at five canopy depths. It includes a leaf energy balance model that is driven by wind speed, humidity, solar insolation, ambient temperature, and soil moisture. The model also calculates whole canopy latent and sensible heat fluxes that can be evaluated by above canopy measurements. Other canopy environment models can be used with MEGAN by setting $\mathrm{C}_{\mathrm{CE}}$ so that $\gamma_{\mathrm{CE}}$ is equal to unity for the MEGAN standard conditions.

The algorithms described by Guenther et al. (1993) and modified by Guenther et al. (1999a) have been used extensively to simulate the response of isoprene emission to changes in light and temperature on a time scale of seconds to minutes. The Guenther et al. (1999a) algorithms simulate emission variations as

$\gamma_{P}=C_{P}\left[(\alpha \cdot \mathrm{PPFD}) /\left(\left(1+\alpha^{2} \cdot \mathrm{PPFD}^{2}\right)^{0.5}\right)\right]$

$\gamma_{T}=E_{\mathrm{opt}} \cdot\left[C_{T 2} \cdot \exp \left(C_{T 1} \cdot x\right) /\left(C_{T 2}-C_{T 1} \cdot\left(1-\exp \left(C_{T 2} \cdot x\right)\right)\right)\right](5)$

where PPFD is the leaf level photosynthetic photon flux density $\left(\mu \mathrm{mol} \mathrm{m}^{-2} \mathrm{~s}^{-1}\right), x=\left[\left(1 / \mathrm{T}_{\mathrm{opt}}\right)-(1 / \mathrm{T})\right] / 0.00831, \mathrm{~T}$ is leaf temperature (K), $\mathrm{C}_{T 1}(=95), \mathrm{C}_{T 2}(=230), \mathrm{C}_{P}, \alpha, \mathrm{E}_{\mathrm{opt}}$, and $\mathrm{T}_{\mathrm{opt}}$ are empirical coefficients. MEGAN extends this algorithm by estimating $\mathrm{C}_{P,}, \mathrm{E}_{\mathrm{opt}}$, and $\mathrm{T}_{\mathrm{opt}}$ using Eqs. (6) through (9) instead of using the constant values recommended by Guenther et al. (1999a). The main advantage of this approach is improved simulations of the variations in isoprene emission associated with past temperature and PPFD conditions. The light and temperature conditions of the past day(s) result in substantial deviations from the Guenther et al. (1993) algorithms that could be due to changes in production of the isoprene substrate, dimethylallyl pyrophosphate (DMAPP), and/or variations in the activity of isoprene synthase (Fall and Wildermuth, 1998), the enzyme that converts DMAPP to isoprene. Variations in DMAPP supply could be due to changes in production, either availability of the carbon precursor (pyruvate) or adenosine triphosphate (ATP) used for phosphorylation, or changes in DMAPP consumption. Variations in isoprene synthase activity and DMAPP have been observed but are not well characterized (Bruggemann et al., 2002; Wolfertz et al., 2003). Isoprene emission rates, measured at standard light and temperature conditions, are higher when warm sunny conditions have occurred during the previous day(s) and are lower if there were cool shady conditions (Sharkey et al., 2000). Petron et al. (2001) found that exposure to high or low temperatures can influence isoprene emission for several weeks. The time required to reach a new, lower, steady-state isoprene emission capacity following a step decrease in temperature was longer than that required to reach a new, higher, equilibrium following an increase in temperature, indicating that down regulation of isoprene emission is a slower process than up regulation. The factors controlling these variations may operate over a continuous range of time scales, but for modeling purposes MEGAN currently considers only 24 and $240 \mathrm{~h}$. The average leaf level PPFD of the past $24 \mathrm{~h}\left(\mathrm{P}_{24}\right)$ and past $240 \mathrm{~h}\left(\mathrm{P}_{240}\right)$ influence the estimated emission activity by adjusting the coefficients in Eq. (4) as follows,

$\alpha=0.004-0.0005 \ln \left(P_{240}\right)$

$C_{P}=0.0468 \cdot \exp \left(0.0005 \cdot\left[P_{24}-P_{0}\right]\right) \cdot\left[P_{240}\right]^{0.6}$

where $\mathrm{P}_{0}$ is equal to $200 \mu \mathrm{mol} \mathrm{m}{ }^{-2} \mathrm{~s}^{-1}$ for sun leaves and $50 \mu \mathrm{mol} \mathrm{m}^{-2} \mathrm{~s}^{-1}$ for shade leaves.

MEGAN estimates the coefficients in Eq. (5) as a function of the average leaf temperature over the past $24\left(\mathrm{~T}_{24}\right)$ and $240\left(\mathrm{~T}_{240}\right) \mathrm{h}$, as follows,

$\mathrm{T}_{\mathrm{opt}}=313+\left(0.6 \cdot\left(\mathrm{T}_{240}-297\right)\right)$

$\mathrm{E}_{\mathrm{opt}}=2.034 \cdot \exp \left(0.05 \cdot\left(\mathrm{T}_{24}-297\right)\right) \cdot \exp \left(0.05 \cdot\left(\mathrm{T}_{240}-297\right)\right)$.(9)

The coefficients used for Eqs. (6-9) are based on observations reported by Petron et al. (2001), Monson et al. (1994), Sharkey et al. (2000), Geron et al. (2000), and Hanson and Sharkey (2001). Although these five studies report results that are qualitatively similar, there remain significant uncertainties associated with these algorithms.

Figure 4 shows the response of $\gamma_{\mathrm{CE}}$ estimates to variations in LAI, solar angle and transmission, and temperature. Isoprene emission increases exponentially with temperature up 
to a maximum that is dependent on the average temperature that the canopy has experienced during the past $240 \mathrm{~h}$. Both the magnitude of the emissions and the temperature at which the maximum occurs are dependent on the past temperature. The result is that MEGAN predicts lower (higher) isoprene emissions in cool (warm) climates than would be simulated by the Guenther et al. (1993) algorithms. However, MEGAN predictions of the isoprene emission response to short term $(<24 \mathrm{~h})$ temperature variations is often less than that predicted by models that do not calculate leaf temperature, e.g., BEIS2/BEIS3 or Guenther et al. (1995). This is because leaf transpiration tends to result in leaf temperature increases that are less than ambient temperature increases.

Above canopy PPFD is determined by solar angle and transmission. MEGAN estimates of $\gamma_{\mathrm{CE}}$ increase nearly linearly with PPFD transmission for canopies that have experienced high PPFD levels (e.g., $24 \mathrm{~h}$ average of $600 \mu \mathrm{mol} \mathrm{m}^{-2} \mathrm{~s}^{-1}$ for sun leaves) during the past day. The emission increase begins to saturate at high PPFD transmission for low solar angles or if the average PPFD has been low during the previous day.

Figure 4 shows that estimated isoprene emission increases nearly linearly with LAI until LAI exceeds $\sim 1.5$ and is nearly constant for $\mathrm{LAI}>5$. The relationship between LAI and $\gamma_{\mathrm{CE}}$ depends on solar angle and on canopy characteristics, which differ with PFT. Isoprene emissions from canopies with clumped leaves increase relatively slowly with increasing $\mathrm{LAI}$ for $\mathrm{LAI}<3$ in contrast to canopies with horizontal leaves that exhibit a stronger LAI dependence for $\mathrm{LAI}<3$. Figure 4 also shows that MEGAN predicts a stronger initial increase with LAI, and a lack of increase with higher LAI, for low solar angles (e.g., <30 degrees).

As an alternative to using a detailed canopy environment model that calculates light and temperature at each canopy depth, we have developed a parameterized approach, referred to here as the parameterized canopy environment emission activity (PCEEA) algorithm, based on the results of the procedures described above. The PCEEA approach for estimating the canopy environment emission activity factor is as follows,

$\gamma_{\mathrm{CE}}=\gamma_{\mathrm{LAI}} \cdot \gamma_{P} \cdot \gamma_{T}$

where $\gamma_{\mathrm{LAI}}, \gamma_{P}$ and $\gamma_{T}$ account for variations associated with LAI, PPFD and temperature. The relationships between these factors and canopy scale isoprene emissions are based on MEGAN canopy environment model simulations for the canopies and environmental conditions that dominate global isoprene emissions (i.e., warm broadleaf forests). The canopy-scale isoprene emission response to PPFD variations is simulated as

$\gamma_{P}=0 \quad a<0, a>180$

$\gamma_{P}=\sin (a)\left[2.46\left(1+0.0005 \cdot\left(P_{\text {daily }}-400\right)\right) \phi \cdot 0.9 \phi^{2}\right]$

$0<a<180$
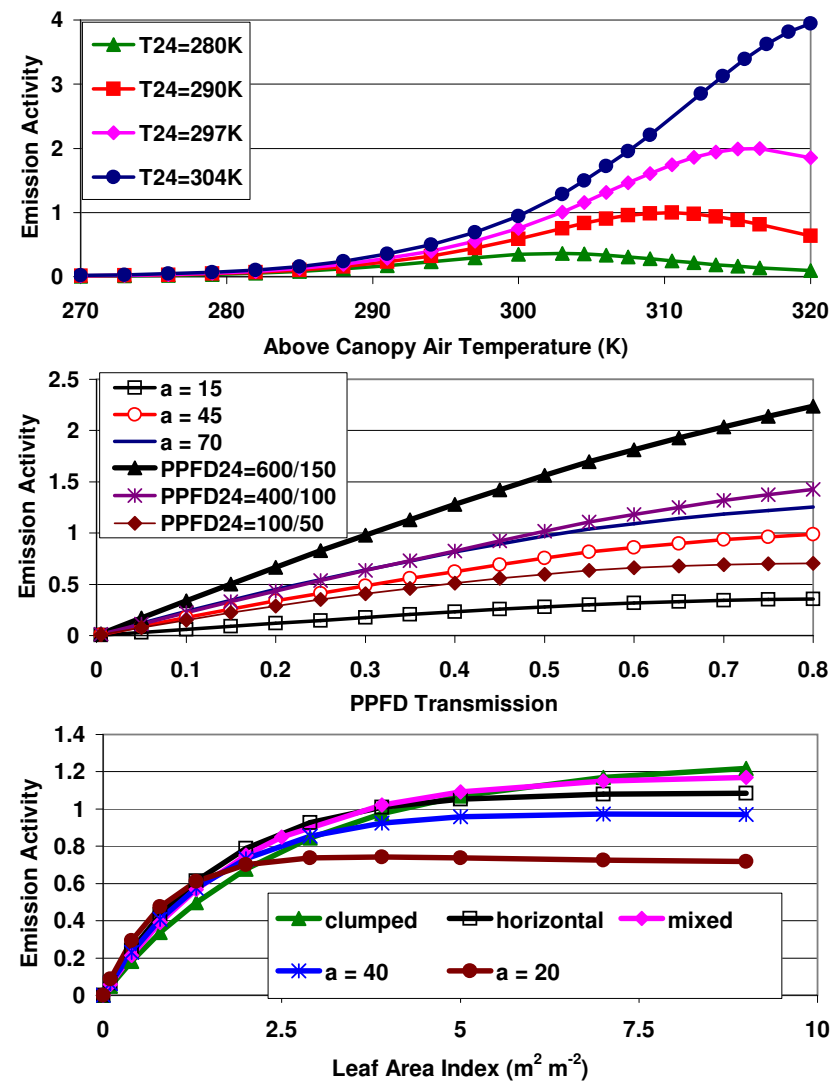

Fig. 4. MEGAN estimates of isoprene emission response to current temperature (top), PPFD transmission (middle) and LAI (bottom). The response to current temperature is estimated for leaves exposed to different average temperatures $(280 \mathrm{~K}, 290 \mathrm{~K}, 297 \mathrm{~K}$ and $305 \mathrm{~K})$ during the past 24 to $240 \mathrm{~h}\left(\mathrm{~T}_{24}=\mathrm{T}_{240}\right.$ in each case). The response to current PPFD transmission is estimated for leaves exposed to different solar angles (15, 45 and 70 degrees) and for average PPFD levels for the past 24 to $240 \mathrm{~h}$ ( $\mathrm{PPFD}_{24}=\mathrm{PPFD}_{240}$ in each case) that include 600 and $150 \mu \mathrm{mol} \mathrm{m}^{-2} \mathrm{~s}^{-1}$, respectively, for sun leaves and shade leaves, 400 and $100 \mu \mathrm{mol} \mathrm{m}^{-2} \mathrm{~s}^{-1}$ for sun and shade leaves, and 100 and $50 \mu \mathrm{mol} \mathrm{m}^{-2} \mathrm{~s}^{-1}$ for sun and shade leaves. The response to LAI (for a constant PPFD transmission of 60\%) is estimated for different canopy leaf orientations (clumped, horizontal and mixed leaves with a solar angle of 60 degrees) and solar angles (20 and 40 degrees with a mixed leaf orientation).

where $P_{\text {daily }}$ is daily average above canopy PPFD $\left(\mu \mathrm{mol} \mathrm{m}^{-2} \mathrm{~s}^{-1}\right)$ representative of the simulation period (typically a week to a month), $a$ is solar angle (degrees) and $\phi$ is above canopy PPFD transmission (non-dimensional) which is estimated as

$\phi=P_{\mathrm{ac}} /\left(\sin (a) P_{\mathrm{toa}}\right)$

where $P_{\text {ac }}$ is above canopy PPFD, $P_{\text {toa }}$ is PPFD $\left(\mu \mathrm{mol} \mathrm{m}{ }^{-2} \mathrm{~s}^{-1}\right)$ at the top of the atmosphere which can be approximated as

$P_{\text {toa }}=3000+99 \cdot \cos (2 \cdot 3.14 \cdot($ DOY -10$) / 365)$

where DOY is day of year. 
The temperature response factor, $\gamma_{T}$, is estimated as

$\gamma_{T}=E_{\mathrm{opt}} \cdot C_{T 2} \cdot \exp \left(C_{T 1} \cdot x\right) /\left(C_{T 2}-C_{T 1} \cdot\left(1-\exp \left(C_{T 2} \cdot x\right)\right)\right)$

where $x=\left[\left(1 / T_{\text {opt }}\right)-\left(1 / T_{h r}\right)\right] / 0.00831, \quad E_{\text {opt }}=1.75 \cdot \exp (0.08$ $\left.\left(T_{\text {daily }}-297\right)\right), T_{h r}$ is hourly average air temperature $(\mathrm{K})$, $T_{\text {daily }}$ is daily average air temperature $(\mathrm{K})$ representative of the simulation period (typically a week to a month), $C_{T 1}$ (=80), $C_{T 2}(=200)$, are empirical coefficients and $T_{\text {opt }}$ is estimated using Eq. (8) with $T_{\text {daily }}$ used in place of $T_{240}$. Emission responses to LAI variations are estimated as

$\gamma_{\mathrm{LAI}}=0.49 \mathrm{LAI} /\left[\left(1+0.2 \mathrm{LAI}^{2}\right)^{0.5}\right]$.

The PCEEA approach is intended for applications that need to minimize the computational resources or have limited availability of driving variables. The PCEEA algorithm estimates annual global isoprene emissions that are within $\sim 5 \%$ of the value estimated using the standard MEGAN canopy environment model. However, differences can exceed $25 \%$ for estimates at specific times and locations.

\subsubsection{Leaf age}

Leaves begin to photosynthesize soon after budbreak but isoprene is not emitted in substantial quantities for days after the onset of photosynthesis (Guenther et al., 1991). In addition, old leaves eventually lose their ability to photosynthesize and produce isoprene. Guenther et al. (1999a) developed a simple algorithm to simulate the reduced emissions expected for young and old leaves based on the observed monthly LAI change. An increase in foliage was assumed to imply a higher proportion of young leaves while decreasing foliage was associated with the presence of older leaves. This algorithm required a time step of one month, assumed that young leaves and old leaves had the same emission rate, and included variables that could not easily be quantified. The following procedures to account for leaf age effects on isoprene emission estimates reduce these deficiencies.

MEGAN assumes a constant value, $\gamma_{\text {age }}=1$, for evergreen canopies. Deciduous canopies are divided into four fractions: new foliage that emits negligible amounts of isoprene $\left(F_{\text {new }}\right)$, growing foliage that emits isoprene at less than peak rates $\left(F_{\text {gro }}\right)$, mature foliage that emits isoprene at peak rates $\left(F_{\text {mat }}\right)$ and old foliage that emits isoprene at reduced rates $\left(F_{\text {old }}\right)$. The canopy-weighted average factor is calculated as

$\gamma_{\text {age }}=F_{\text {new }} A_{\text {new }}+F_{\text {gro }} A_{\text {gro }}+F_{\text {mat }} A_{\text {mat }}+F_{\text {old }} A_{\text {old }}$

where $A_{\text {new }}(=0.05), A_{\text {gro }}(=0.6), A_{\text {mat }}(=1.125)$, and $A_{\text {old }}$ $(=1)$ are the relative emission rates assigned to each canopy fraction. The values of these emission factors are based on the observations of Petron et al. (2001), Goldstein et al. (1998), Monson et al. (1994), Guenther et al. (1991) and Karl et al. (2003).

The canopy is divided into leaf age fractions based on the change in LAI between the current time step $\left(\mathrm{LAI}_{c}\right)$ and the previous time step $\left(\mathrm{LAI}_{p}\right)$. In cases where $\mathrm{LAI}_{c}=\mathrm{LAI}_{p}$ then $F_{\text {mat }}=0.8, F_{\text {new }}=0, F_{\text {gro }}=0.1, F_{\text {old }}=0.1$. When $\operatorname{LAI}_{p}>\mathrm{LAI}_{c}$ then $F_{\text {new }}$ and $F_{\text {gro }}$ are equal to zero, $F_{\text {old }}$ is estimated as $\left[\left(\mathrm{LAI}_{p}-\mathrm{LAI}_{c}\right) / \mathrm{LAI}_{p}\right]$ and $F_{\mathrm{mat}}=1-F_{\text {old }}$. In the final case, where $\mathrm{LAI}_{p}<\mathrm{LAI}_{c}, F_{\text {old }}=0$ and the other fractions are calculated as

$$
\begin{aligned}
& F_{\text {new }}=1-\left(\operatorname{LAI}_{p} / \mathrm{LAI}_{c}\right) \text { for } t<=t_{i} \\
& F_{\text {new }}=\left[t_{i} / t\right]\left[1-\left(\mathrm{LAI}_{p} / \mathrm{LAI}_{c}\right)\right] \text { for } t>t_{i} \\
& F_{\text {mat }}=\left(\mathrm{LAI}_{p} / \mathrm{LAI}_{c}\right) \text { for } t<=t_{m} \\
& F_{\text {mat }}=\left(\mathrm{LAI}_{p} / \mathrm{LAI}_{c}\right)+\left[\left(t-t_{m}\right) / t\right]\left[1-\left(\mathrm{LAI}_{p} / \mathrm{LAI}_{c}\right)\right] \text { for } t>t_{m} \\
& F_{\text {gro }}=1-F_{\text {new }}-F_{\text {mat }}
\end{aligned}
$$

where $t$ is the length of the time step (days) between $\mathrm{LAI}_{c}$ and $\mathrm{LAI}_{p}, t_{i}$ is the number of days between budbreak and the induction of isoprene emission, $t_{m}$ is the number of days between budbreak and the initiation of peak isoprene emission rates, and $t_{g}=t_{m}$ for $t>t_{m}$ and $t_{g}=t$ for $t \leq t_{m}$. The time step, $t$, depends on the LAI database that is used but generally is between one week and one month. Petron et al. (2001) grew plants under conditions typical of temperate regions and observed an emission pattern that suggests a $t_{i}$ of about 12 days and $t_{m}$ of about 28 days. Goldstein et al. (1998) field observations in a temperate forest indicate a similar value for $t_{m}$. Monson et al. (1994) found that $t_{i}$ and $t_{m}$ are temperature dependent and are considerably less for vegetation growing at high temperatures. These observations suggest that the temperature dependence of these variables can be estimated as

$t_{i}=5+\left(0.7 \cdot\left(300-T_{t}\right)\right)$ for $t_{i} \leq 303$

$t_{i}=2.9$ for $t_{i}>303$

$t_{m}=2.3 \cdot t_{i}$

where $T_{t}$ is the average ambient air temperature $(\mathrm{K})$ of the preceding time step interval. MEGAN simulations using a constant $t_{i}$ and $t_{m}$ result in global annual isoprene emissions that are $\sim 5 \%$ lower than estimates based on a variable $t_{i}$. However, the emission rates estimated using variable $t_{i}$ and $t_{m}$ can be as much as $20 \%$ higher in tropical regions and $20 \%$ lower in boreal regions when foliage is rapidly expanding. The differences are more pronounced when LAI variations have a higher time resolution (i.e., weekly rather than monthly). Equations (18) and (19) are important for higher resolution simulations and when foliage is expanding but otherwise have only a minimal impact on estimated emissions.

\subsubsection{Soil moisture}

Plants require both carbon dioxide and water for growth. Carbon dioxide is taken up through leaf stomatal openings and water is usually obtained from the soil. However, large quantities of water are lost through stomata creating a need 
for adequate soil moisture in order to continue carbon uptake. Field measurements have shown that plants with inadequate soil moisture can have significantly decreased stomatal conductance and photosynthesis, in comparison to wellwatered plants, and yet can maintain approximately the same isoprene emission rates (Guenther et al., 1999b). However, isoprene emission does begin to decrease when soil moisture drops below a certain level and eventually becomes negligible when plants are exposed to extended severe drought (Pegoraro et al., 2004). MEGAN can simulate the response of isoprene emission to drought through two mechanisms. Isoprene emissions are indirectly influenced by the soil moisture dependence of stomatal conductance which influences the leaf temperature estimated by the MEGAN canopy environment model. In addition, MEGAN includes an emission activity factor, dependent on soil moisture, estimated as

$$
\begin{aligned}
& \gamma_{\mathrm{SM}}=1 \quad \theta>\theta_{1} \\
& \gamma_{\mathrm{SM}}=\left(\theta-\theta_{w}\right) / \Delta \theta_{1} \quad \theta_{w}<\theta<\theta_{1} \\
& \gamma_{\mathrm{SM}}=0 \quad \theta<\theta_{w}
\end{aligned}
$$

where $\theta$ is soil moisture (volumetric water content, $\mathrm{m}^{3} \mathrm{~m}^{-3}$ ), $\theta_{w}\left(\mathrm{~m}^{3} \mathrm{~m}^{-3}\right)$ is wilting point (the soil moisture level below which plants cannot extract water from soil) and $\Delta \theta_{1}(=0.06)$ is an empirical parameter based on the observations of Pegoraro et al. (2004), and $\theta_{1}=\theta_{w}+\Delta \theta_{1}$. MEGAN uses the high resolution $\left(\sim 1 \mathrm{~km}^{2}\right)$ wilting point database developed by Chen and Dudhia (2001) which assigns $\theta_{w}$ values that range from 0.01 for sand to $0.138 \mathrm{~m}^{3} \mathrm{~m}^{-3}$ for clay soils. Soil moisture varies significantly with depth and the ability of a plant to extract water is dependent on root depth. MEGAN uses the PFT dependent approach described by Zeng (2001) to determine the fraction of roots within each soil layer and applies the weighted average $\gamma_{S M}$ for each soil layer. This approach allows soil moisture estimates from any soil depth to be used in Eq. (20).

Including the influence of soil moisture on isoprene emission (Eq. 20) reduces annual global isoprene emissions by only $\sim 7 \%$ but can reduce regional emissions to zero for days to months. As expected, the soil moisture emission activity factor has the greatest impact on isoprene emissions estimated for arid regions. However, significant reductions in estimated emissions also occur in regions that have moderate to high total annual precipitation but also have dry seasons with little rainfall.

\subsubsection{Other factors that influence isoprene emission activ-} ity

Isoprene emission activity can also be influenced by other environmental conditions including ozone (Velikova et al., 2005) and carbon dioxide (Buckley, 2001; Rosenstiel et al., 2003) concentrations, nitrogen availability (Harley et al., 1994), and physical stress (e.g., Alessio et al., 2004). In addition, there may be significant diurnal variations that are not entirely explained by variations in environmental conditions (Funk et al., 2003). Emission activity factors accounting for these processes will be included in MEGAN as more reliable algorithms are developed. Existing observations have been used to qualitatively assess the importance of these factors and are discussed in Sect. 6.

\subsection{Canopy loss and production, $\rho$}

Chemicals emitted into the canopy airspace do not always escape to the above-canopy atmosphere. Some molecules are consumed by biological, chemical and physical processes on soil and vegetation surfaces while others react within the canopy atmosphere. Some emissions escape to the abovecanopy atmosphere in a different chemical and/or physical (i.e., gas to particle conversion) form. MEGAN includes a factor, $\rho$, that accounts for losses and transformations in the canopy. The resulting emission estimate is a net canopy emission but is not the net flux. The net ecosystematmosphere isoprene flux is the sum of the MEGAN net emission rate estimate and an above-canopy deposition rate that can be estimated from an above-canopy concentration and a deposition velocity. The MEGAN canopy loss factor for isoprene, $\rho_{\text {ISO,ISO }}$, is the ratio of isoprene emitted into the above canopy atmosphere to the isoprene emitted into the canopy atmosphere. Additional factors account for the emission of gases and aerosols produced from the oxidation of isoprene within the canopy. For example, the MEGAN canopy production factor for the isoprene oxidation prod-

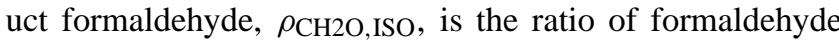
(produced from isoprene oxidation) emitted into the above canopy atmosphere to the isoprene emitted into the canopy atmosphere.

Inverse modeling of within-canopy gradients of isoprene suggests that at least $90 \%$ of the isoprene emitted by tropical and temperate forests escapes to the above-canopy atmosphere (Karl et al., 2004; Stroud et al., 2005). The remainder is removed through a combination of chemical losses and dry deposition. While ambient mixing ratios within the canopy and roughness layer can change on the order of 10-30\% due to chemistry (Makar et al., 1999), the bias of canopy scale isoprene flux measurements is small (i.e., on the order of 5 $10 \%)$. This can be attributed to (1) near field effects within the canopy and (2) limited processing time between the location of isoprene emission (occurring mostly within the upper canopy) and the top of the canopy. Comparisons between canopy-scale emissions based on leaf-level emission measurements extrapolated with a canopy environment model and above-canopy flux measurements tend to show that any loss of isoprene is less than the uncertainty associated with these two approaches (Guenther et al., 1996; Guenther et al., 2000; Spirig et al., 2005).

Variations in isoprene canopy production and loss are estimated as

$\rho_{\text {ISO }, \text { ISO }}=1-D /\left[\lambda \cdot u^{*} \cdot \tau+D\right]$ 
where $D$ is canopy depth $(\mathrm{m}), \mathrm{u}^{*}$ is friction velocity $\left(\mathrm{m} \mathrm{s}^{-1}\right)$, $\tau$ is the above-canopy isoprene lifetime (s) and $\lambda$ is an empirically determined parameter. Canopy depth is the distance from the top to the bottom of the canopy and can be considerable less than canopy height. Equation (21) is parameterized with the above-canopy isoprene lifetime, rather than the within-canopy lifetime, because this is the value more readily available for atmospheric modeling. $D$ and $\lambda$ are PFT dependent and are assigned $D=15$ and $\lambda=0.3$ for the generic PFT-1 canopy. Since values of $\rho_{\text {ISO,ISO }}$ range only from 0.93 to 0.99 for most conditions, Table 1 includes assigning a constant value, $\rho_{\text {ISO,ISO }}=0.96$ for isoprene emission estimation efforts. The variability is greater for more reactive compounds such as the sesquiterpene, $\beta$-caryophyllene, for which the canopy loss factor $\rho_{\mathrm{CARY}}$, CARY can vary from $<0.1$ to $>0.6$ depending on environmental conditions. Equation (21) is based on measured isoprene emission profiles and turbulence profiles obtained during recent tropical and temperate forest field studies (Karl et al., 2004; Stroud et al., 2005). The variation of the isoprene lifetime inside the canopy was scaled to the above-canopy lifetime and based on measured $\mathrm{O}_{3}$ profiles and modeled $\mathrm{OH}$ and $\mathrm{NO}_{3}$ levels reported by Stroud et al. (2005). A random walk model similar to the one described by Baldocchi (1997) and Strong et al. (2004) was used to estimate the first order decay of isoprene. Trajectories for 5000 particles were released at 4 levels and computed for typical daytime conditions. The chemical loss by the ensemble mean was used to assess $\rho_{\text {ISO,ISO }}$ integrated over the whole canopy.

Model simulations of the impact of isoprene on atmospheric chemistry depend on estimates of net isoprene emission as well as estimates of the regional uptake of isoprene and its oxidation products, e.g. methylvinylketone, methacrolein and peroxyacetyl nitrate (PAN), from the above-canopy atmosphere. Karl et al. (2004) conclude that current model procedures can underestimate the uptake of these oxidation products which would cause an overestimate of the impact of isoprene on oxidants and other atmospheric constituents. They also report that isoprene oxidation products deposit more rapidly during night than predicted by standard dry deposition schemes. During daytime, the net effect of deposition and in-canopy production of these compounds can be on the same order. These observations raise the possibility that various products of isoprene chemistry are taken up by the forest canopy more efficiently then previously assumed. This could lead to an incorrect characterization of the impact of isoprene by chemistry and transport models that have correctly simulated isoprene emission rates and oxidation schemes, and could explain why some chemistry and transport models are forced to use isoprene emission rates that are lower than observed.

\section{Driving variables}

The MEGAN algorithms described in Sect. 3 require estimates of landcover (LAI and PFT distributions) and weather (solar transmission, air temperature, humidity, wind speed, and soil moisture) conditions. The standard driving variables used for MEGAN are described in this section and are compared with alternative databases.

\subsection{Leaf area}

MEGAN requires leaf area estimates with a time step of $\sim 4$ to 40 days in order to simulate seasonal variations in leaf biomass and age distribution. MEGAN does not assume that LAI is uniformly spread over a grid cell but assumes that foliage covers only that part of the grid cell containing vegetation. The average LAI for vegetated areas is estimated by dividing the grid average LAI by the fraction of the grid that is covered by vegetation. We refer to this as LAIv (the LAI of vegetation covered surfaces) and we set an upper limit of LAIv $=6$ to eliminate the very high values that can be estimated for grids with very little vegetation. The standard MEGAN LAIv database (MEGAN-L) was estimated by this approach using the LAI estimates of Zhang et al. (2004) and estimates of vegetation cover fraction from Hansen et al. (2003). These data were processed to include values for missing data and urban areas.

Figure 5 illustrates how LAIv variations with time and location result in isoprene emission variations of more than an order of magnitude, independent of variation in other driving variables which are held constant in these simulations. These emission variations are driven by changes in only leaf age and quantity. Isoprene is reduced by more than a factor of five at higher latitudes in winter but varies only $\sim 15 \%$ for croplands, forests and grasslands during the growing season. Most of the extra-tropical regions of the southern hemisphere do not exceed a level of $30 \%$ of the maximum emission while tropical forests regions rarely fall below a level of $70 \%$.

Table 4 includes descriptions of six LAI databases that have been used to estimate global isoprene emissions with MEGAN. Satellite-derived LAI estimates provide high resolution variability but are not available for all years. Dynamic vegetation models allow predictions of past and future emissions. The MEGAN-L database contains monthly estimates for years 2000 to 2005 at $30 \mathrm{~s}\left(\sim 1 \mathrm{~km}^{2}\right)$ resolution. Table 4 includes a comparison of annual global isoprene emissions estimated with alternative LAIv databases. The estimates range from $11 \%$ lower to $29 \%$ higher than the MEGAN-L values. Some of the differences are due to interannual variations, which can be seen in Fig. 6 by the comparison of July average isoprene emissions estimated with the AVHRR3 databases for years 1990 and 2000. The emission estimates using MODIS based estimates of LAI, including the MEGAN-L database, are generally 20\% lower than emission estimates using the other LAI databases. All of the 


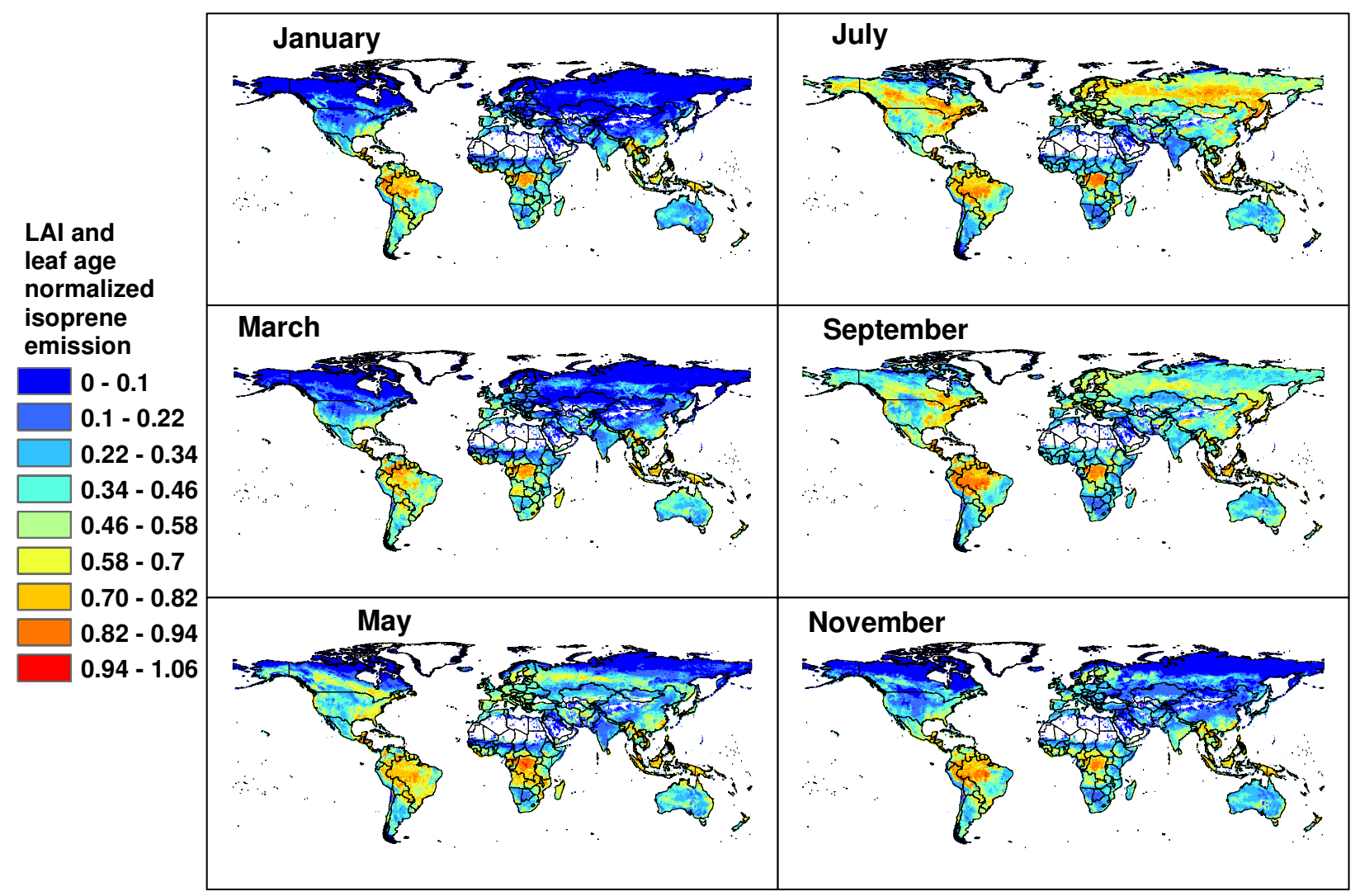

Fig. 5. Monthly normalized isoprene emission rates estimated with MEGAN for 2003. Rates are normalized by the emission estimated for standard LAI $\left(=5 \mathrm{~m}^{2} \mathrm{~m}^{-2}\right)$ and leaf age ( $80 \%$ mature leaves). These normalized rates illustrate the variations associated with changes in only LAI and leaf age; i.e. all other model drivers are held constant.

databases shown in Fig. 6 have regions of more than a factor of 3 lower emissions and regions with more than a factor of 3 higher emissions. However, the regions with the greatest percent differences tend to be areas with relatively low emissions.

\subsection{PFT distributions}

The PFT databases described in Table 4 use a variety of inputs including satellite observations, vegetation inventories, ecosystem maps, and ecosystem model output. The satellite data provide the highest spatial and temporal resolution while only models can be used to simulate future scenarios. Vegetation inventories based on field observations are expected to provide the most accurate estimates of PFT distributions but they have limited coverage.

Landcover data were processed to generate the MEGAN PFT categories from each data source shown in Table 4. Landcover data that included PFT estimates (AVHRR1-P, MODIS1-P), were converted into the MEGAN PFT scheme with a straightforward collapsing of their fifteen PFTs into the seven MEGAN PFTs. The ecosystem scheme databases (HYDE, GED, IBIS, IMAGE, MODIS2, SPOT) contain a discrete landcover type for each location that is based on either observed vegetation distribution maps, vegetation model output or satellite observations. A PFT distribution was assumed for each ecosystem type in each database. For example, the temperate mixed forest ecosystem in the GED database was assumed to be composed of $20 \%$ broadleaf deciduous trees, $20 \%$ broadleaf evergreen trees, $40 \%$ needle evergreen trees, $1 \%$ needle deciduous trees, $1 \%$ shrubs, $1 \%$ crops, $2 \%$ herbaceous and $15 \%$ bare ground or water. These subjective PFT assignments were based on qualitative descriptions of the ecosystems. The IMAGE database includes estimates for years 2000 and 2100 and the HYDE database has estimates for 50 year intervals between 1700 and 1950 and 20 year intervals between 1950 and 1990 . The AVHRR2 and MODIS3 databases use satellite derived tree cover data that include total cover, and deciduous and broadleaf fractions. These provide the most direct estimates for the MEGAN tree PFTs and constrain the total fraction assigned to the other three MEGAN PFTs. The standard MEGAN PFT database (MEGAN-P) combines the MODIS3 database with quantitative tree inventories based on ground observations where available (e.g., Kinnee et al., 1997). The global distribution of each PFT in the MEGAN database is 
Table 4. MEGAN global input databases. Annual global isoprene emissions estimated for alternative (present day) databases are compared (\% difference) to the emission estimated with the standard (MEGAN-P, MEGAN-L and MEGAN-W) databases.

\begin{tabular}{|c|c|c|c|c|c|c|c|}
\hline $\begin{array}{l}\text { Data } \\
\text { type }\end{array}$ & Name & $\begin{array}{l}\text { Spatial } \\
\text { scale }\end{array}$ & $\begin{array}{l}\text { Time } \\
\text { period }\end{array}$ & description & $\begin{array}{l}\text { Base } \\
\text { data }\end{array}$ & $\begin{array}{l}\text { Global Emission } \\
\text { (\% difference) }\end{array}$ & Base data reference \\
\hline PFT & AVHRR1-P & $\sim 50 \mathrm{~km}$ & $\sim 2000$ & PFT & AVHRR & $-7 \%$ & Bonan et al. (2002) \\
\hline PFT & MODIS1-P & $\sim 50 \mathrm{~km}$ & $\sim 2000$ & PFT & MODIS & $+15 \%$ & Tian et al. (2004) \\
\hline PFT & MODIS2 & $\sim 50 \mathrm{~km}$ & $\sim 2000$ & ecosystem & MODIS & $+18 \%$ & Friedl et al. (2002) \\
\hline PFT & G95-P & $\sim 50 \mathrm{~km}$ & $\sim 2000$ & ecosystem & Inventory & $+2 \%$ & Olson (1992) \\
\hline PFT & HYDE & $\sim 50 \mathrm{~km}$ & $1700-1990$ & ecosystem & Model, inventory & $-13 \%$ & Klein Goldewijk et al. (2001) \\
\hline PFT & IMAGE & $\sim 50 \mathrm{~km}$ & $2000-2100$ & ecosystem & Model & $-11 \%$ & Alcamo et al. (1998) \\
\hline PFT & MAPPS-P & $\sim 50 \mathrm{~km}$ & 2000,2100 & ecosystem & Model & $+24 \%$ & Neilson (1995) \\
\hline PFT & IBIS & $\sim 8 \mathrm{~km}$ & 1992 & ecosystem & Model, inventory & $+3 \%$ & Ramankutty and Foley (1999) \\
\hline PFT & SPOT & $\sim 1 \mathrm{~km}$ & $\sim 2000$ & ecosystem & SPOT & $-7 \%$ & http://www-gvm.jrc.it/glc2000/ \\
\hline PFT & AVHRR2 & $\sim 1 \mathrm{~km}$ & $\sim 2000$ & land char. & AVHRR & $+2 \%$ & DeFries (2000); Hansen (2000) \\
\hline PFT & MODIS3 & $\sim 1 \mathrm{~km}$ & $\sim 2000$ & land char. & AVHRR/MODIS & $-0.3 \%$ & DeFries (2000); Hansen (2003) \\
\hline PFT & MEGAN-P & $\sim 1 \mathrm{~km}$ & 2001 & land char. & MODIS, inventory & standard case & Kinnee et al. (1997) \\
\hline LAI & AVHRR1-L & $\sim 50 \mathrm{~km}$ & $\sim 2000$ & Monthly & AVHRR & $-11 \%$ & Bonan et al. (2002) \\
\hline LAI & MODIS1-L & $\sim 50 \mathrm{~km}$ & $\sim 2000$ & Monthly & MODIS & $+12 \%$ & Tian et al. (2004) \\
\hline LAI & AVHRR3 & $\sim 50 \mathrm{~km}$ & $1981-2000$ & Monthly & AVHRR & $+25 \%$ & Myneni et al. (1997) \\
\hline LAI & G95-L & $\sim 50 \mathrm{~km}$ & $\sim 2000$ & Monthly & model, AVHRR & $+24 \%$ & Guenther et al. (1995) \\
\hline LAI & MAPSS-L & $\sim 50 \mathrm{~km}$ & $\sim 2000,2100$ & Monthly & model & $+29 \%$ & Neilson (1995) \\
\hline LAI & MEGAN-L & $\sim 1 \mathrm{~km}$ & $2000-2005$ & Monthly & MODIS & standard case & Zhang et al. (2004) \\
\hline Weather & IIASA & $\sim 50 \mathrm{~km}$ & 1960-1990 mean & Hourly & observations & $+13 \%$ & Leemans and Cramer (1992) \\
\hline Weather & CRU & $\sim 50 \mathrm{~km}$ & $1900 s-1980 s$ & Hourly & observations & $-11 \%$ & $\mathrm{a}$ \\
\hline Weather & HadCM2 & $\sim 300 \mathrm{~km}$ & $1980 \mathrm{~s}, 2080 \mathrm{~s}$ & Hourly & A1 scenario & +15 & $\mathrm{~b}$ \\
\hline Weather & CSM1 & $\sim 300 \mathrm{~km}$ & $1990 \mathrm{~s}, 2090 \mathrm{~s}$ & Hourly & A1 scenario & $-11 \%$ & $\mathrm{c}$ \\
\hline Weather & MEGAN-W & $\sim 200 \mathrm{~km}$ & 1979-2004 & Hourly & NCEP obs/model & standard case & Kanamitsu et al. (2002) \\
\hline Weather & MM5 & $\sim 100 \mathrm{~km}$ & 2001-2004 & Hourly & MM5 obs/model & $-14 \%$ & Dudhia and Bresch (2002) \\
\hline
\end{tabular}

${ }^{a}$ http://ipcc-ddc.cru.uea.ac.uk/obs/get_30yr_means.html

${ }^{\mathrm{b}} \mathrm{http}: / /$ ipcc-ddc.cru.uea.ac.uk/sres/hadcm2_download/is $92 / \mathrm{gcm}$ data.html

${ }^{c}$ http://www.ccsm.ucar.edu/experiments/ccsm1.0/b030.A1/

shown in Fig. 7. The regions dominated by broadleaf trees are the major global isoprene sources. Shrubs dominate at high latitudes, where, despite relatively high emission factors, cool weather generally results in low isoprene emissions. However, shrubs have a fairly wide global distribution and so contribute to isoprene emissions in many regions.

Global vegetation cover area estimated with the eleven databases ranges from about 90 to $120 \times 10^{6} \mathrm{~km}^{2}$, which represents $\sim 60$ to $80 \%$ of the global land surface. Most of the PFT database estimates are within $\sim 10 \%$ of the mean value of $104 \times 10^{6} \mathrm{~km}^{2}$. While there is considerable variation in estimates of crops, grass/other and needle deciduous tree areas, these PFTs make only a small contribution to the global total isoprene emission. Shrub and needle evergreen tree area estimates from the different PFT databases agree relatively well. Area estimates of broadleaf trees, which contribute half of the total global isoprene emission, are more variable and thus are a significant component of the overall uncertainty in global annual emissions. However, the sum of total broadleaf tree area plus shrub area is less variable and all but one database is within $20 \%$ of the $40 \times 10^{6} \mathrm{~km}^{2}$ of broadleaf tree plus shrub area estimated by the MEGAN-P database. Figure 8 shows that large differences in regional isoprene emission estimates ( $>$ factor of 4 ) are obtained using the dif- ferent PFT databases. All of the databases have areas of both lower and higher emission so that the global total estimates, shown in Table 4, range only from $13 \%$ lower to $24 \%$ higher than the value estimated with the MEGAN-P database.

Ecosystem databases can be used to generate reasonable estimates of annual global isoprene emissions but may not produce accurate regional distributions. For example, the 72 ecosystem types in the GED database used for the Guenther et al. (1995) emission inventory were assigned PFT distributions that resulted in a global annual emission within a few percent of the MEGAN-P database, but Fig. 8 shows that there are large regional differences.

Global total emissions from all of the databases derived directly from $1 \mathrm{~km}$ resolution satellite data agree reasonably well. However, large global total differences in PFT area estimates occur among databases that are based on MODIS observations but use different procedures to assign PFT areas. This indicates that the method for assigning PFT cover has a greater effect than the satellite sensor that is used. Approaches (e.g., DeFries et al., 2000) that use continuous vegetation fields (e.g. percent tree cover, percent broadleaf vegetation, percent herbaceous cover) provide more objective PFT distributions. 


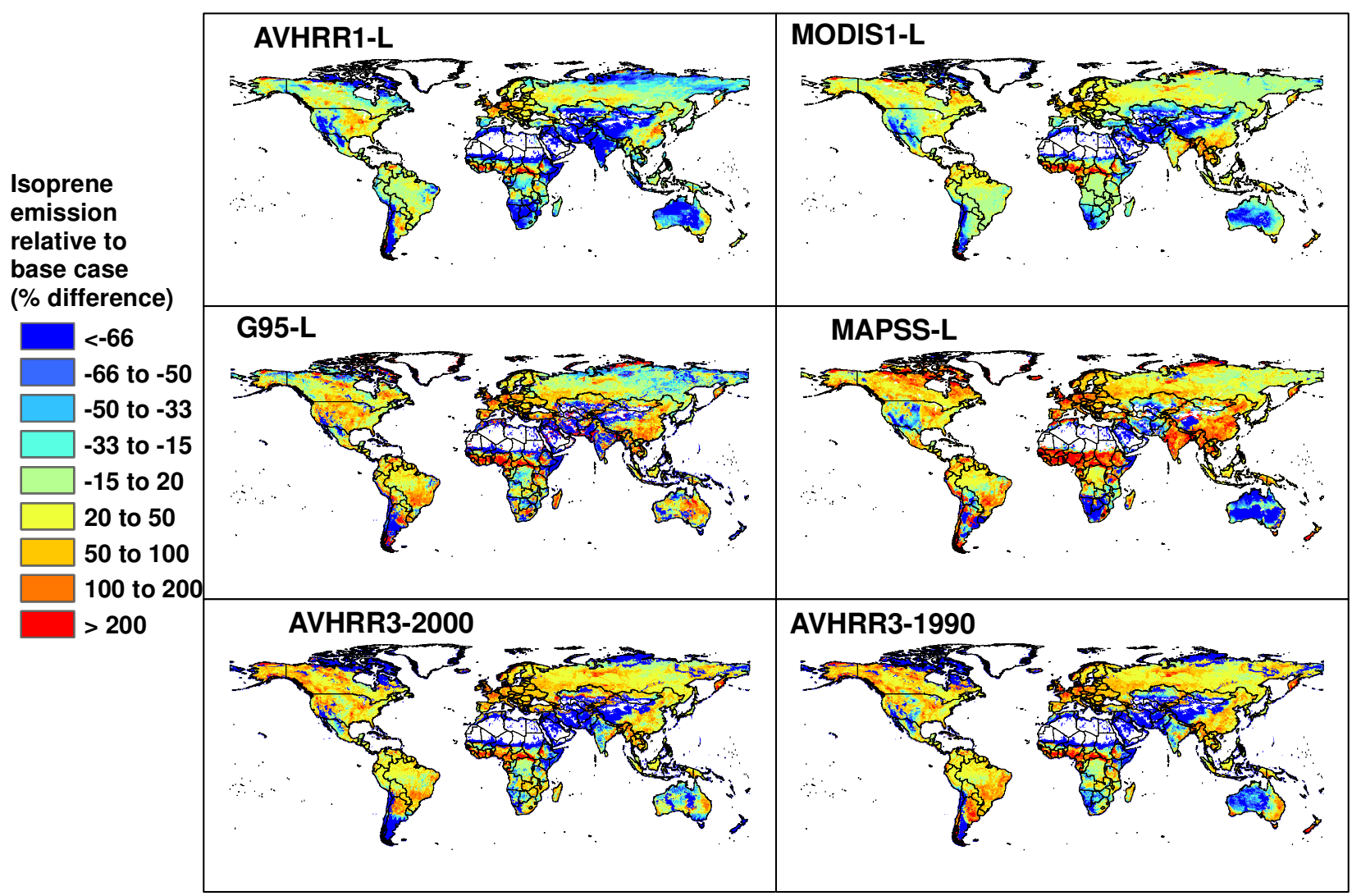

Fig. 6. Percent difference in July 2003 average isoprene emission estimated by MEGAN with the LAI databases described in Table 2 in comparison with the standard MEGAN-L database.

\subsection{Weather}

MEGAN weather input variables include ambient temperature, PPFD, humidity, wind speed and soil moisture. Figure 9 shows that both seasonal and spatial weather variations can result in monthly average isoprene emission estimates that vary by more than an order of magnitude. In particular, the cool weather conditions at high latitudes result in much lower isoprene emissions. Previous estimates of seasonal variations in tropical rainforests have fairly constant monthly emission rates (Guenther et al., 1995) but MEGAN estimates much larger (factor of 3 ) variations. These large seasonal variations are a result of the MEGAN algorithms that account for the influence of the weather of the past 24 to $240 \mathrm{~h}$. These predictions generally agree with the substantial seasonal variations in isoprene emissions reported for tropical rainforest sites (e.g., Guenther et al., 1999a; Andreae et al., 2002; Trostdorf et al., 2004) but additional observations are needed for a rigorous evaluation.

The sensitivity of MEGAN hourly isoprene emission estimates to different global weather data was examined using the databases listed in Table 4. These include estimates based on interpolated observations (IIASA and CRU), estimates from global weather models with assimilated obser- vations (NCEP-DOE reanalysis and MM5), and two global climate models (HadCM2 and CSM1). The NCEP-DOE reanalysis, which is the only one that included soil moisture, was used as the standard database (MEGAN-W). The NCEPDOE soil moisture was used to estimate $\gamma_{\mathrm{SM}}$ for all emission estimates. Hourly estimates were generated from 4 times daily values for MEGAN-W, MM5 and CSM1 data and from monthly mean values for IIASA, CRU and HadCM2. Hourly temperature and PPFD variations were estimated for an average day for each month for the latter databases. The annual global emission estimated for the five alternative databases are within $\sim 15 \%$ of the MEGAN-W estimate. However, regional estimates differ by as much as a factor of two to three for specific locations and months. The difference in isoprene emission estimated for alternatives of the same database type (e.g., observational) is similar to the level of difference between database types (e.g., observational compared to climate models).

The Guenther et al. (1995) isoprene emission estimates used the IIASA database without including diurnal temperature variations (which underestimated emissions) but also used a method for estimating PPFD from cloud cover (based on Pierce and Waldruff, 1991) that overestimated emissions. The two compensating errors resulted in an annual global 


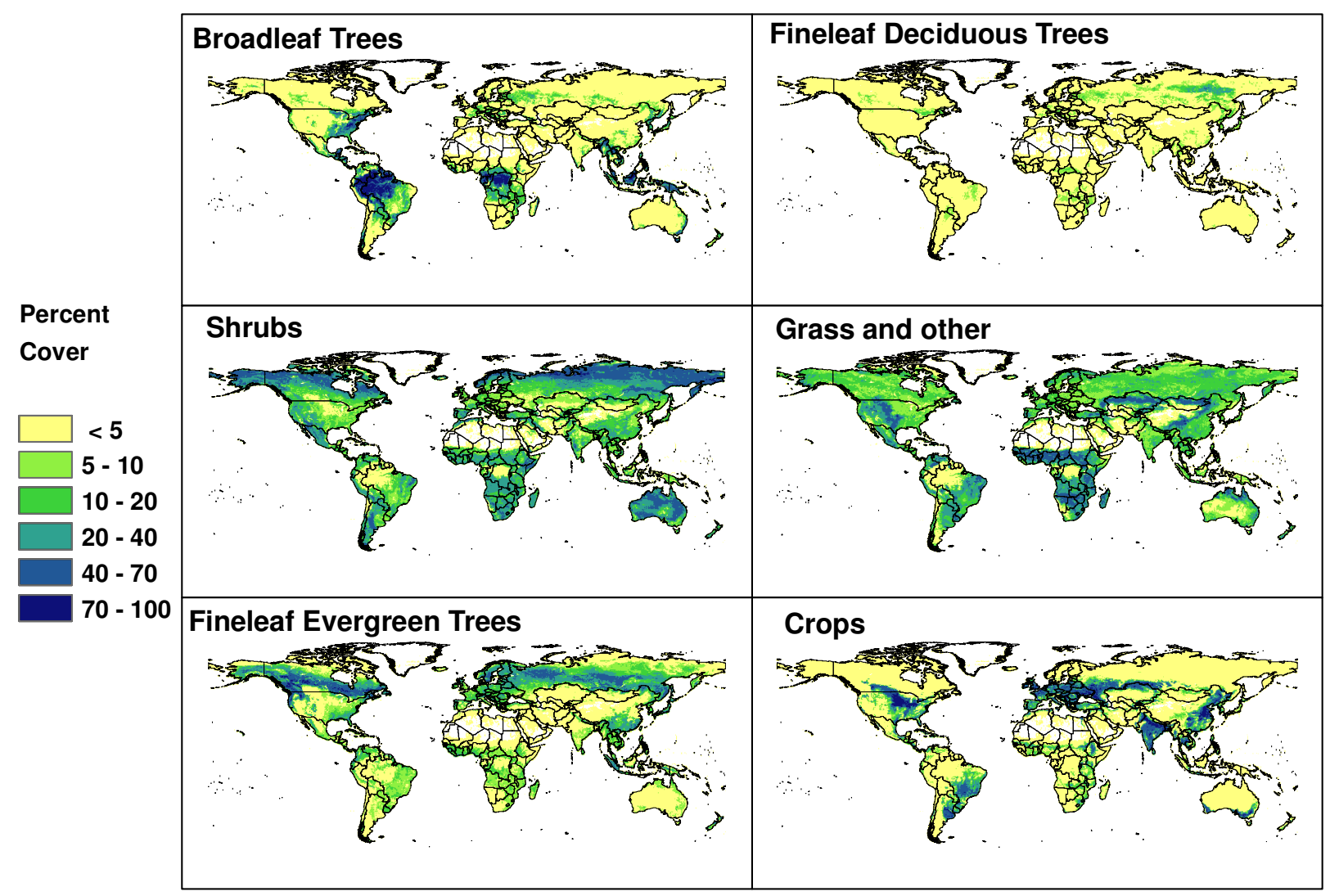

Fig. 7. Global distributions of the MEGAN PFTs.

emission estimate that is within $\sim 3 \%$ of the emission based on a diurnal temperature range and more accurate estimates of surface solar radiation.

\section{Isoprene emission estimates}

Guenther et al. (1995) estimated a global annual emission of $\sim 570 \mathrm{Tg}$ of isoprene (503 Tg of carbon), which was somewhat higher than prior estimates which had ranged from $\sim 200-500 \mathrm{Tg}$ of isoprene. The higher emission estimate of Guenther et al. (1995) is primarily due to increased emission factors, although there were also substantial differences in other model components. Earlier isoprene emission factor measurements tended to underestimate the canopy average emissions because they were biased towards leaves and branches from the lower part of the canopy or were otherwise not representative. Wang et al. (1998) used methods similar to Guenther et al. (1995) and estimated a global annual isoprene emission that was $\sim 20 \%$ higher. This difference was attributed to the use of a diurnal temperature cycle, rather than monthly average temperatures.

\subsection{MEGAN isoprene emission estimates}

The annual global isoprene emission estimated by MEGAN using the standard MEGAN input databases for year 2003 is $\sim 600 \mathrm{Tg}$ isoprene. This estimate is similar to the annual global emission (570 Tg isoprene) reported by Guenther et al. (1995). The contribution of individual PFTs and biomes to the total global emission estimated using MEGAN is shown in Table 3. Emissions from tropical broadleaf trees are nearly half of the total flux. Tropical (28\%), arid land $(11 \%)$ and temperate $(4.5 \%)$ shrub emission estimates indicate an important source, yet there are very few emission measurements from these shrubs. Temperate broadleaf trees contribute $\sim 5 \%$ of the estimated total.

Monthly average isoprene emissions estimated using MEGAN with the standard driving variables are shown in Fig. 10. Emissions range from $>150 \mathrm{mg}$ isoprene $\mathrm{m}^{-2} \mathrm{day}^{-1}$ (e.g., some locations in Australia, eastern U.S., and Amazon) to $<1 \mathrm{mg}$ isoprene $\mathrm{m}^{-2}$ day $^{-1}$ (e.g., higher latitudes in winter). Figures 5 through 9 show that monthly variation in isoprene distributions are controlled by weather and, to a lesser degree, by LAI variations.

Isoprene emission estimates based on the 20 year AVHRR3 LAIv database indicates that interannual LAI variations result in $\sim 4 \%$ variation in global annual isoprene 


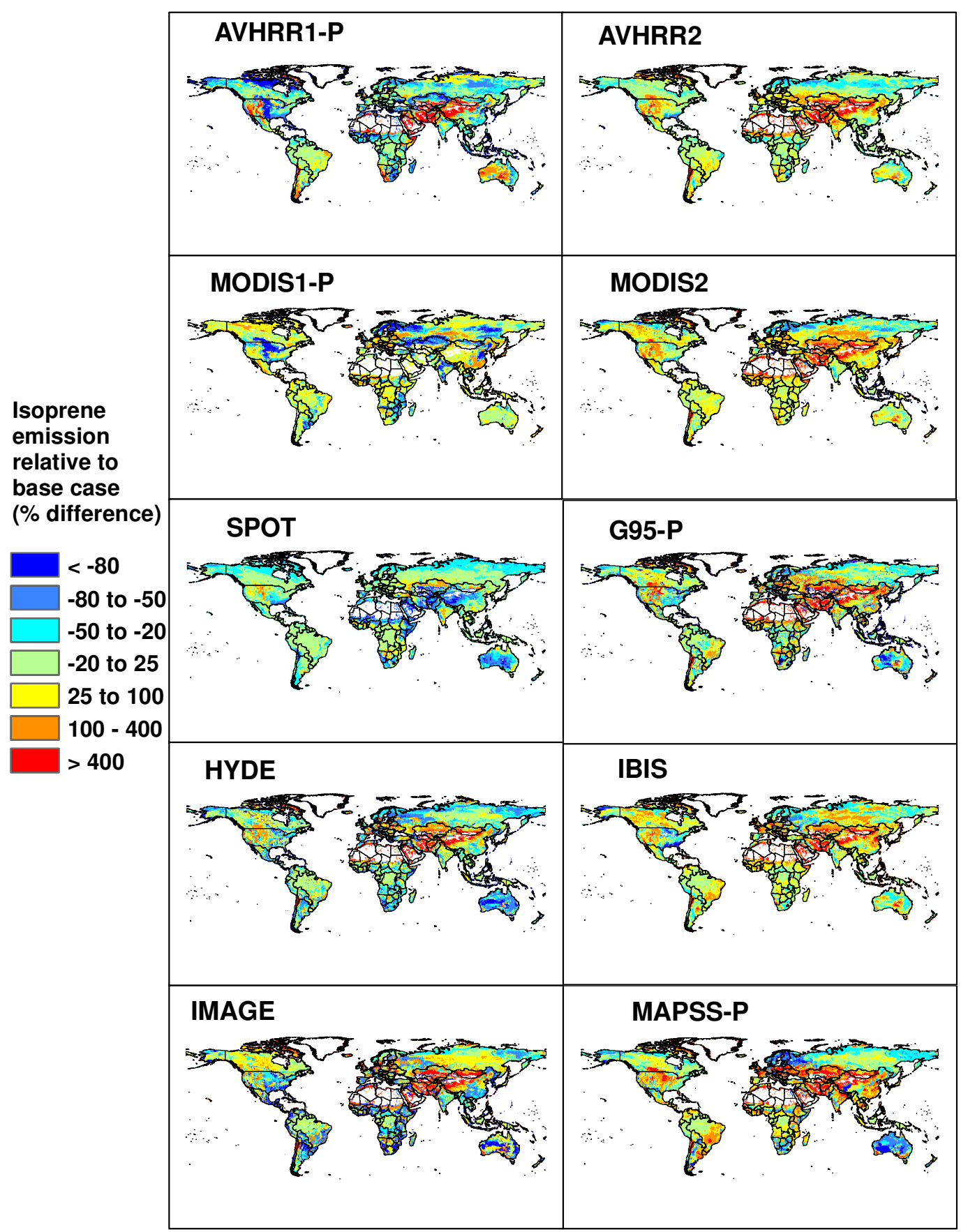

Fig. 8. Percent difference in July 2003 average isoprene emission estimated by MEGAN with the PFT databases described in Table 2 in comparison with the standard MEGAN-P database.

emissions. However, isoprene emission estimates for specific regions and months, especially arid landscapes and boreal forests, vary by more than $30 \%$ due to interannual LAI variations. NCEP-DOE database interannual weather variations for years 1996 to 2004 result in 8\% variation in global annual isoprene emissions but differences for specific months and locations exceed $50 \%$.
The annual global isoprene emission estimated by MEGAN using the alternative driving variable databases, listed in Table 4 , range from $\sim 15 \%$ lower to $\sim 30 \%$ higher. Weather, PFT and LAI databases all contribute to these differences in estimated emissions. Emission estimates for specific regions and months can differ by more than a factor of 3 but are typically within $\sim 30 \%$ for the regions that dominate global emissions. 


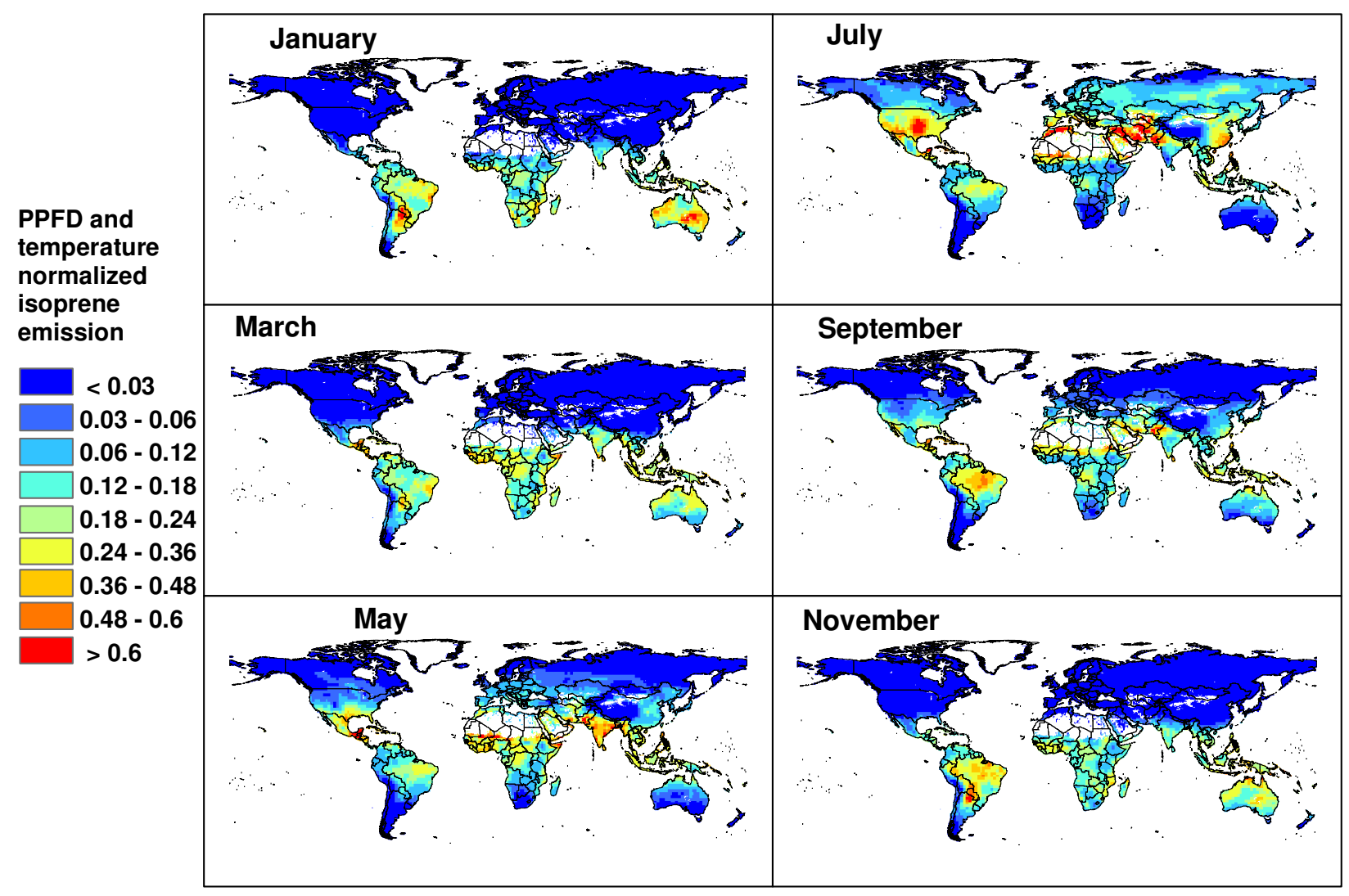

Fig. 9. Monthly normalized isoprene emission rates estimated with MEGAN for 2003. Rates are normalized by the emission estimated for standard temperature $(=303 \mathrm{~K})$ and PPFD transmission $(60 \%)$. These normalized rates illustrate the variations associated with changes only in temperature and PPFD transmission; i.e. all other model drivers are held constant.

\subsection{Top-down emission estimates using satellite observa-} tions

Recent studies have demonstrated that formaldehyde (HCHO) column data from the Global Ozone Monitoring Experiment (Palmer et al., 2001) provide important constraints to regional and global isoprene emission estimates (e.g., Abbot et al., 2003; Palmer et al., 2003; Shim et al., 2005). Formaldehyde is a high yield oxidation product of VOCs. Palmer et al. (2003) developed a methodology to relate $\mathrm{HCHO}$ columns to emissions of its parent VOC, taking into account the lifetimes of $\mathrm{HCHO}$ and the VOC.

Over North America during the growing season, isoprene is the dominant contributor to measured HCHO columns (Palmer et al., 2003). The spatial distribution and magnitude of GOME HCHO columns is consistent with in situ surface data (Palmer et al., 2003); and the seasonal and interannual variability of $\mathrm{HCHO}$ columns is broadly consistent with MEGAN isoprene emission estimates (Abbot et al., 2003). Typical monthly mean values for GOME HCHO columns over North America during summer months are $1-2.5 \times 10^{16}$ molec $\mathrm{cm}^{-2}$, with the largest values over the Southeast United States (Fig. 11); the fitting uncertainty of the columns is $\sim 4 \times 10^{15}$ molec $\mathrm{cm}^{-2}$. Isoprene emissions, estimated from these data using a regression between modeled isoprene fluxes and modeled HCHO columns, have an estimated uncertainty of $\sim 30 \%$ (Palmer et al., 2006). This study also found that MEGAN isoprene flux estimates were within a factor of 2 of above-canopy fluxes measured over a growing season in northern Michigan $(\mathrm{r}=0.55)$. Past work has shown that GOME isoprene emission estimates are spatially correlated with BEIS2 isoprene emission estimates but have a significant positive bias, and have a negative bias relative to the Guenther et al. (1995) isoprene emission estimates (Palmer et al., 2003). There remain a number of differences between GOME and MEGAN isoprene emission estimates in both the magnitude and the distribution of isoprene emissions, particularly over the Southeast United States (Fig. 11). These discrepancies could be due to a number of unresolved issues with both the model chemistry and MEGAN estimates.

The HCHO yield from isoprene oxidation has been the subject of only a few studies (e.g., Atkinson and Arey, 2003, and references therein) but the intermediate chemical kinetics are generally thought to be fairly well known at $\mathrm{NO}_{\mathrm{x}}$ levels $>1$ ppbv, as often experienced over North America. 


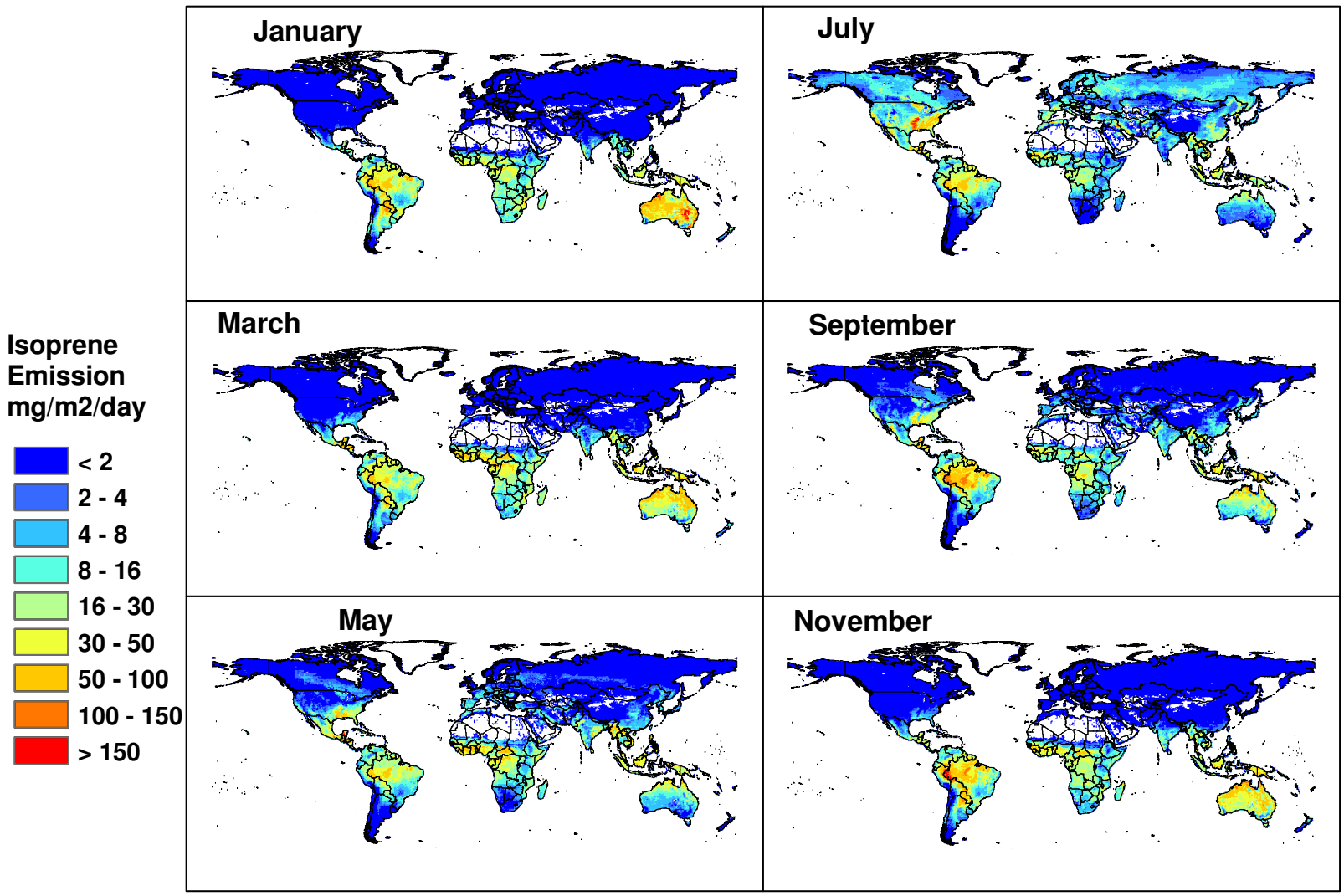

Fig. 10. Monthly average isoprene emission rates estimated with MEGAN for 2003.

JUNE
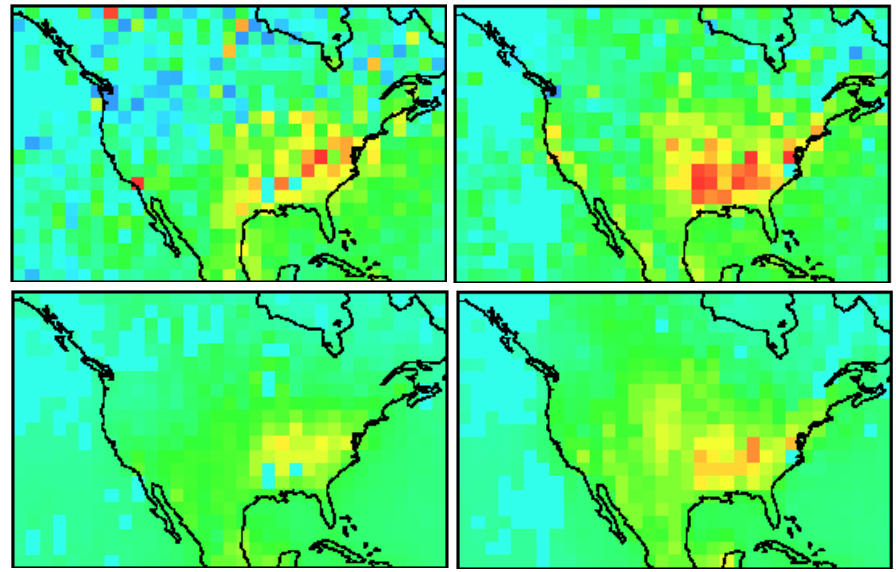

AUGUST
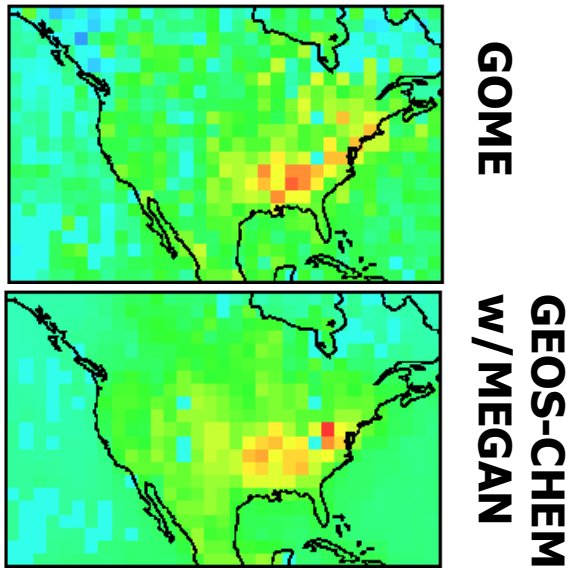

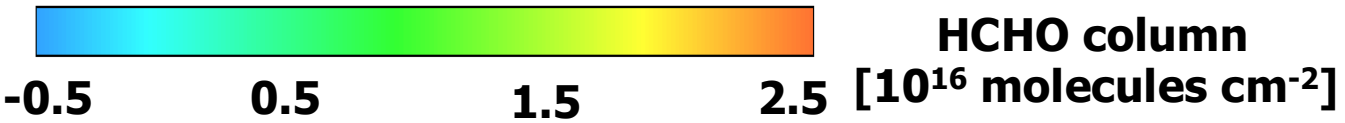

Fig. 11. Monthly mean HCHO columns over North America for June-August 2001. GOME observed (top panels) and GEOS-CHEM modeled using MEGAN (bottom panels) vertical columns are shown on a 2×2.5 degree grid for 10:00-12:00 LT and for cloud cover $<40 \%$. 
Terpenes, sesquiterpenes, and other highly reactive VOCs emitted by vegetation, also lead to the production of $\mathrm{HCHO}$ but current model calculations suggest that they make a relatively small contribution to observed HCHO columns (Palmer et al., 2006). Better quantitative understanding of the HCHO yields from these reactive VOCs is required. Work has begun to assess the role of anthropogenic hydrocarbons on the observed HCHO column signal. Aircraft observations during the Texas Air Quality Study in AugustSeptember 2000 (Wert et al., 2003) saw HCHO plumes of $100 \mathrm{~km}$ length originating from a number of smoke stacks close to Houston; the primary source of this HCHO was saturated alkenes (Wert et al., 2003). Analysis of GOME data does not show an enhancement over these regions (Martin et al., 2004), possibly due its crude horizontal resolution $\left(320 \times 40 \mathrm{~km}^{2}\right)$. However, Martin et al. (2004) found that anthropogenic VOCs play a role in determining $\mathrm{HCHO}$ columns over eastern Texas although biogenic VOCs appear to dominate on a regional scale. The role of anthropogenic VOCs in determining HCHO columns is a subject of ongoing work, but taking into account these possible contaminations to the analysis of the observed HCHO columns will not explain the model discrepancy in the observed seasonal variability shown by Fig. 11. It is possible that the GOME data is observing a large-scale stress factor that affects isoprene emissions (e.g., ozone) but is not accounted for by MEGAN.

Initial studies of GOME HCHO data have focused on North America because there is a relative abundance of in situ observations with which to evaluate the $\mathrm{HCHO}$ column data and the methodology used to estimate isoprene emissions (Palmer et al., 2003). Extending this analysis to the rest of the world is clearly desirable but requires careful separation of the biomass burning and anthropogenic contributions to HCHO from the biogenic signal, as discussed above. Taking this difficulty into consideration, Shim et al. (2005) conducted Bayesian inversions for 10 biogenic, biomass burning, and industrial sources over 8 separate continental regions based on GOME HCHO measurements. GEOS-CHEM was used as the forward model. Over the selected inversion regions, isoprene is the major contributor to the observed variability of HCHO columns. They showed that the posteriori isoprene emissions are generally higher at northern mid latitudes but lower in the tropics compared to the Guenther et al. (1995) estimates. The posteriori annual global isoprene emission estimate is $641 \mathrm{Tg}$ isoprene which is only $7 \%$ higher than the MEGAN estimate for 2003. The posteriori biomass burning HCHO sources are higher by a factor of 24 over the regions with significant biomass burning except for India. The industrial HCHO sources are higher by $\sim 20 \%$ except for northern East Asia and India $(\sim 60 \%)$. The posteriori uncertainties of isoprene emissions are greatly reduced but are still high at $\sim 90 \%$, reflecting the relatively large uncertainties in GOME retrievals.

\section{Isoprene emission response to earth system changes}

Isoprene emissions are a dynamic part of the earth system and respond to changes in the physical, chemical and biological components of this system. Our current limited understanding of the likely response of isoprene emissions to these changes is based primarily on studies using greenhouse grown plants. Additional studies are needed under realistic growth conditions that include synergistic variables. Predictions of future isoprene emissions are very challenging due to the uncertainties in characterizing future physical, chemical and biological variables and the isoprene emission response to each. Potential interactions add additional complications. It is difficult to predict even the sign of the response of isoprene emission to the multiple effects of some driving variables. For example, increasing $\mathrm{CO}_{2}$ levels may reduce isoprene emission activity (a direct effect) but increase LAI and the abundance of isoprene emitters (indirect effects).

Figure 12 illustrates MEGAN predictions of the response of July average isoprene emissions to past and future changes in PFT distributions, LAI and weather using the databases described in Table 4. Estimates of PFT changes generally indicate that isoprene emissions have increased in the past 50 to 300 years and will decrease over the next 50 to 100 years. This is primarily due to simulated changes in agricultural land use and is dependent on the assumed PFT distributions. Future increases in isoprene are predicted for some regions due to climate driven PFT and LAI changes. Future temperature simulations predict a substantial increase in isoprene emissions in most regions. Predicted changes in PPFD result in increased emissions in some regions and decreases in other regions. The MEGAN estimates clearly show that isoprene emissions are sensitive to earth system changes but there are large uncertainties associated with these estimates and it is currently not possible to make robust predictions of future changes in isoprene emissions. The potential importance of the known driving variables is discussed below.

\subsection{Physical climate}

Physical climate influences isoprene emissions through physiological and ecological processes that operate on different time scales. The relationship between isoprene emission and these driving variables is non-linear and the response depends on canopy structure, climate (e.g., a temperature increase in a warm climate may have a different effect than in a cool climate), and the temporal and spatial pattern of these changes. MEGAN isoprene emission estimates increase with increasing leaf temperature which is primarily driven by air temperature but is also influenced by solar radiation, humidity, wind speed and soil moisture. MEGAN isoprene emission estimates are less sensitive to air temperature changes than they would be if the model assumed that leaf temperature is equal to air temperature. This behavior reflects the ability of broadleaf canopies to minimize leaf temperature 


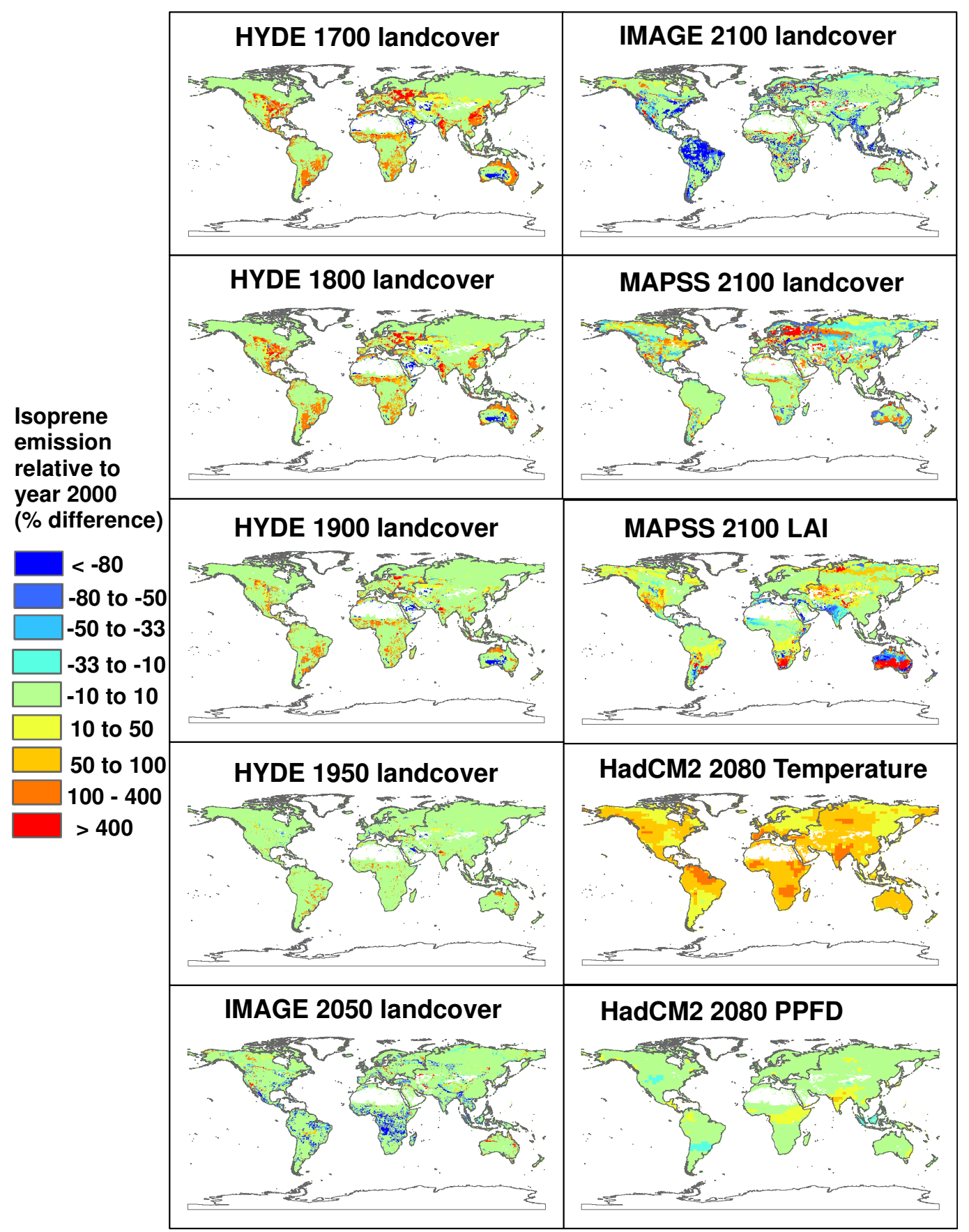

Fig. 12. Percent difference (future/past-present) in July average isoprene emission estimated by MEGAN with past/future databases (Table 2) in comparison with MEGAN present day estimates.

increases by transpiring. However, this ability is diminished during drought conditions. MEGAN predicts a greater response to changes in temperature and PPFD than models that use the Guenther et al. (1993) algorithms which account only for short term temperature and PPFD variations. Thus MEGAN isoprene emission estimates are more sensitive to long-term changes in temperature and PPFD. Model simu- lations of isoprene emission response to long-term climate variations are difficult to evaluate due to a lack of observational studies that are needed to characterize this behavior. In addition to the direct effects of climate, estimates of longterm changes in isoprene emissions must also consider the indirect effects of climate-driven changes in vegetation. Our ability to predict the response of isoprene to these vegetation 
changes is limited both by uncertainties in model predictions of these changes and uncertainties in assigning emission factors to the landcover types used in these models.

Previous studies have described the potential sensitivity of isoprene emissions to long-term (centuries) changes in physical climate. Adams et al. (2001) estimate that global isoprene emissions are presently more than a factor of 2 higher than they were during the last glacial maximum. The estimated increase was associated with the direct effect of higher leaf temperature, resulting in a $60 \%$ increase in isoprene emissions, and the indirect effect of climate-induced changes in vegetation distributions, resulting in a $40 \%$ increase in isoprene emissions. They note that lower BVOC emissions during the last glacial maximum would significantly increase $\mathrm{OH}$ which could contribute to the low methane concentrations observed in ice core samples. Several studies have examined the response of global isoprene emission to potential future climate (Turner et al., 1991; Sanderson et al., 2003; Wiedinmyer et al., 2006). Turner et al. predict that climateinduced landcover changes will result in a $25 \%$ increase in isoprene emissions while Sanderson et al. and Wiedinmyer et al. predict slight $(\sim 5 \%)$ decreases in isoprene emission. All three studies predict a much larger (35\% to $70 \%$ ) increase associated with increased temperature. They all assumed a similar isoprene emission response to temperature change so it is likely that the differences in estimated emissions are primarily due to differences in the climate model predictions.

MEGAN simulations using the IMAGE and MAPSS-P PFT databases predict isoprene emission responses to future (year 2100) PFT distributions that range from a 30\% decrease with IMAGE to a $6 \%$ increase with MAPSS. The difference is primarily because IMAGE accounts for changes in cropland area while MAPSS does not. MEGAN isoprene emission distributions shown in Fig. 12 demonstrate that these changes vary considerably for different regions. These MEGAN simulations, and the results of previous studies described above, demonstrate that future PFT changes could result in significant isoprene emission variations, especially at regional scales, but it is difficult to even predict whether these PFT changes will result in an increase or decrease in emissions.

Global climate model predictions of future PPFD result in small $(\sim 5 \%)$ changes in annual global isoprene emissions that range from a small increase (HadCM2) to a small decrease (CSM1). CSM1 estimates of future PPFD resulted in regional isoprene emission changes ranging from about $-50 \%$ to $+50 \%$. The isoprene emission changes associated with HadCM2 PPFD estimates are shown in Fig. 12 and range from $-16 \%$ to $+58 \%$. Solar radiation trends observed at sites in the U.S., China and other locations (e.g., Liepert, 2002; Che et al., 2005) indicate that substantial reductions $(>10 \%)$ in solar transmission have occurred in many regions in the past four decades. The response of isoprene emission is sensitive to the pattern of solar radiation decrease, i.e., whether there is an increase in the number of overcast days or a change in the transmission on clear days, but Fig. 4 shows that isoprene emission is expected to decrease nearly linearly with solar transmission.

The response of isoprene to future temperature increases is highly dependent on the model and scenario used to predict future temperatures. For a given prediction of future temperature increases, the associated isoprene emission increase predicted by MEGAN is $\sim 40 \%$ higher than what would be predicted by previous studies (e.g., Turner et al., 1991; Sanderson et al., 2003; Wiedinmyer et al., 2006). This is because MEGAN includes algorithms (Eqs. 8 and 9) that account for changes in the temperature of the past 24 to $240 \mathrm{~h}$. As a result, MEGAN predicts that annual global isoprene emissions in the year 2100 could be more than a factor of 2 higher than present day emissions. Isoprene emission increases of more than a factor of 3 are estimated for some regions. PPFD and temperature variations tend to be correlated which can result in larger increases in isoprene emissions. For example, the HadCM2 simulation predicts a $4 \%$ increase in annual global emission due to PPFD alone and a $72 \%$ increase due to temperature alone. An increase of $81 \%$ is estimated when both PPFD and temperature are considered.

There are large uncertainties associated with predictions of the response of isoprene emission to future temperature changes. Uncertainties include predictions of future temperature conditions (the climate models listed in Table 4 predict temperatures that differ by several degrees $\mathrm{K}$ ), indirect effects on landcover characteristics and the direct response of isoprene emission (e.g., Eqs. 8 and 9). However, much of the difference between the MEGAN estimates described in this paper and the results of previous modeling studies is due to the addition of an algorithm for simulating long term temperature variations (i.e., Eq. 8). The need for this type of algorithm is clearly demonstrated by the broad agreement between observational studies (e.g. Sharkey et al., 2000; Geron et al., 2000; Petron et al., 2001; Hanson and Sharkey, 2001) showing that over periods of days to weeks, plants adapt to higher temperatures by increasing their emission rates more than would be expected by observing their response to diurnal temperature variations alone. MEGAN assumes this phenomenon is applicable to temperature changes on annual to decadal time scales as well, although this remains to be demonstrated.

\subsection{Chemical climate}

Laboratory and field enclosure measurements have shown that the chemical composition of the atmosphere can influence isoprene emission rates (e.g., Rosenstiel et al., 2003; Velikova et al., 2005). Aerosols in the atmosphere or deposited on leaf surfaces can indirectly influence isoprene emissions by modifying light levels. Atmospheric nitrogen, ozone, and $\mathrm{CO}_{2}$ concentrations can have both direct and indirect impacts on isoprene emissions. The indirect effects are 
associated with their ability to influence climate and plant species distributions. The direct effects are related to biochemical and physiological responses.

Isoprene emission from plants can be significantly suppressed by high $\mathrm{CO}_{2}$ concentrations (Rosenstiel et al., 2003) but minimal decreases have been observed in some field studies (Buckley, 2001; Rapparini et al., 2004). Pegoraro et al. (2004) found that isoprene emission correlates with internal $\mathrm{CO}_{2}$ concentration which is a function of ambient $\mathrm{CO}_{2}$ levels and stomatal conductance. A lower stomatal conductance, which occurs with higher vapor pressure deficits and water stress, reduces the internal $\mathrm{CO}_{2}$ concentration and so can reduce the impact of elevated $\mathrm{CO}_{2}$ levels on isoprene emission. This suggests that the elevated $\mathrm{CO}_{2}$ concentrations that can substantially decrease isoprene emission from well-watered plants will have less of an impact under most field conditions. Elevated $\mathrm{CO}_{2}$ tends to increase foliar density which can result in an increase in isoprene emission. Centritto et al. (2004) found that a decrease in isoprene per unit leaf area was balanced by increased leaf area associated with elevated $\mathrm{CO}_{2}$ levels. However, isoprene emission from most plant canopies is limited by light and not leaf area, so increased foliage will have the greatest impact on isoprene emission from open canopies. Elevated $\mathrm{CO}_{2}$ concentrations may result in changes in species distributions, which can also have a significant but generally unpredictable impact on landscape average isoprene emission factors. This has the potential to significantly impact isoprene emissions but it is not known how this will affect regional to global scale isoprene emission.

Harley et al. (1994) observed a strong correlation between nitrogen fertilization and isoprene emission from potted plants. This indicates that increased nitrogen availability from fertilizer application or atmospheric deposition could lead to elevated isoprene emissions. Field studies of this phenomenon are needed in order to assess the potential impact on regional or global isoprene emissions.

Large increases in the emission of isoprene have been observed from leaves exposed to short-term elevated ozone levels (Velikova et al., 2005). The response occurs rapidly and persists for hours after ozone levels are reduced. In contrast, Ennis et al. (1990) found that isoprene emission did not respond to long term exposure to elevated ozone. This may indicate that isoprene emissions are not influenced by the long-term average ozone but respond only when plants are exposed to short-term ozone concentration fluctuations. The response of isoprene emissions to ozone and other stresses is likely complex and a reliable description of this behavior will require a better understanding of the biochemical and physiological processes that control emissions.

\subsection{Land management}

Landscape-scale isoprene emissions are very sensitive to changes in foliar density and species composition that are a direct or indirect result of land management practices. Examples of practices that have had major impacts on regional isoprene emissions include overgrazing, cropland abandonment, tree plantations, selective logging, fire suppression and urbanization. Guenther et al. (1999a) examined the response of a subtropical rangeland to overgrazing. They estimate that a shrub invasion associated with overgrazing resulted in a factor of 3 increase in isoprene emissions. Schaab et al. (2000) simulated the effects on regional isoprene emissions of cropland-to-woodland conversion in southern France over a 35-year period and estimated that regional isoprene emissions increased by a factor of four $(\sim 50 \%$ increase per decade). The impact of urbanization on isoprene emission is dependent on the landscape that is being converted and on urban tree planting practices. Cities in drier regions tend to have more vegetation than the natural landscape while cities in wetter regions typically have less vegetation than the potential natural state. The recognition that some vegetation has very high VOC emission rates could lead municipal governments to recommend or mandate the planting of trees with low isoprene emissions.

Tree plantations represent a small fraction $(\sim 5 \%)$ of total forest land but they dominate in some regions and the global total is rapidly increasing. The total land area covered by tree plantations has increased by about a factor of 10 in the past century, with much of the increase in the tropics. Landcover inventories (e.g., FAO, Global Forest Resource Assessment 2000, National Forestry Action Plans (NFAP) / Forest Resources Assessment (FRA), FAO http: //www.fao.org/forestry/fo/fra/index.jsp, 2001) indicate that at least half of this land area is covered by bamboo or trees (e.g., Eucalyptus, Cocos, Elaeis, Casuarina, Picea, Populus, Salix and Platanus) with high isoprene emissions that are likely to cause a large regional increase (greater than a factor of 10) in isoprene emission. While the impact of this land management activity on global scale emissions is currently minimal, the regional perturbations could be significant.

Fire suppression during the past century has led to large increases in tree foliar density distributions in many regions (e.g., the western United States). Increased foliar density is expected to increase isoprene emissions but the change in species composition may be equally important. Brown and Smith (2000) summarize the response of various ecosystems to fire and note that large changes in species composition occur with varying fire frequency. Fire resistant species include trees that emit isoprene (e.g., oaks) and those that do not (e.g., pines). The impact of fire suppression on isoprene emission appears to be ecosystem dependent but is likely to result in large emission changes in many ecosystems. 


\section{Conclusions and implications for atmospheric chem- istry modeling}

Global geographically-referenced estimates of isoprene emission are necessary for characterizing global carbon cycling, distributions of trace gases and aerosols and their radiative forcing, and investigations of regional air quality (Guenther, 2002; Geron et al., 1994; Sanderson et al., 2003). The isoprene emission rates recommended in the mid to late 1990s (e.g., Guenther et al., 1995; Pierce et al., 1998) were more than a factor of two greater than those previously used in regional air quality models and global chemistry and transport models (e.g., Zimmerman et al., 1979; Pierce and Waldruff, 1991; Muller, 1992). The higher isoprene emission rates resulted in unrealistically high predictions of boundary layer isoprene and ozone concentrations when they were introduced into some chemistry and transport models (e.g., Houweling et al., 1998). This led to the development of global isoprene emission inventories that were based on the Guenther et al. (1995) geographical and seasonal emission distributions but included a scaling factor to uniformly reduce emissions by $20 \%$ or more (e.g., Houweling et al., 1998; Poisson et al., 2000) or reduce isoprene emissions by as much as a factor of three in selected landscapes (Bey et al., 2001). The Intergovernmental Panel on Climate Change (IPCC) Working Group on Atmospheric Chemistry and Greenhouse Gases (Ehhalt and Prather, 2001) recommended using a global isoprene emission rate that is $56 \%$ lower than the Guenther et al. (1995) estimates. This emission reduction was used to produce chemistry and transport model simulations of $\mathrm{CO}$ and isoprene concentrations that were similar to observations. However, the poor model performance could have been due to factors other than isoprene emission rates. For example, deposition rates, chemical oxidation schemes, or boundary layer dynamics could have been responsible. The ability of other models (e.g., Granier et al., 2000; Sanderson et al., 2003) to simulate reasonable distributions of chemical constituents when using annual global isoprene emissions of $\sim 500 \mathrm{Tg}$ carbon $(\sim 570 \mathrm{Tg}$ isoprene), indicates that the rates estimated by Guenther et al. (1995) and by MEGAN are not unrealistic. Future improvements in simulations of the relevant chemical, physical, and biological processes in global chemistry and transport models may provide stronger constraints on isoprene emissions. At present, these models neither confirm nor disprove the validity of the emission rates estimated by MEGAN. However, top-down emission estimates based on satellite measurements of formaldehyde distributions (see Sect. 6.2) generally agree with the emission rates estimated by MEGAN.

While considerable progress has been made in improving our understanding of the processes controlling isoprene emission rates for some regions and seasons, substantial uncertainties remain. Robust algorithms that accurately predict the response of isoprene emission to long term changes in the physical (e.g., temperature and light) and chemical (e.g., carbon dioxide and ozone) environments are needed and require additional observations, primarily by using enclosure methods with controlled environments. Advances in aircraft regional flux measurement capabilities and top-down remote sensing approaches will improve our ability to constrain regional to global scale isoprene emissions. The isoprene emission calculation methods developed for MEGAN require significant refinement but are currently suitable for chemistry and transport modeling on regional and global scales.

Acknowledgements. We are grateful to G. Pfister (NCAR) and R. Wright (USEPA) for valuable comments on this manuscript. We thank U. Vanchindorj and H.-M. Hsu for processing some of the landcover and weather datasets and Angie Jardine for assistance in creating some figures. P. I. Palmer acknowledges support from the NASA Atmospheric Composition Modeling and Analysis Program and the Atmospheric Chemistry Program of the U.S. National Science Foundation. This work was partially supported by an interagency agreement from the USEPA National Risk Management Lab in Research Triangle Park, NC. The National Center for Atmospheric Research is sponsored by the National Science Foundation.

Edited by: F. J. Dentener

\section{References}

Abbot, D., Palmer, P., Martin, R., Chance, K., Jacob, D., and Guenther, A.: Seasonal and interannual variability of isoprene emissions as determined by formaldehyde column measurements from space, Geophys. Res. Lett., 17, 1886, doi:10.1029/2003GL017336, 2003.

Adams, J., Constable, J., Guenther, A., and Zimmerman, P.: An estimate of natural volatile organic compound emissions from vegetation since the last glacial maximum, Chemosphere- Global Change Science, 3, 73-91, 2001.

Alcamo, J., Leemans R., and Kreileman, E. (Eds.): Global change scenarios of the 21 st century. Results from the IMAGE 2.1 model, Pergamon \& Elseviers Science, London, pp. 296, 1998.

Alessio, G. A., De Lillis, M., Fanelli, M., Pinelli, P., and Loreto, F.: Direct and indirect impacts of fire on isoprenoid emissions from Mediterranean vegetation, Functional Ecology, 18(3), 357-364, 2004.

Andreae, M. O., Artaxo, P., Brandao, C., Carswell, F. E., Ciccioli, P., da Costa, A. L., Culf, A. D., Esteves, J. L., Gash, J., and Grace, J.: Biogeochemical cycling of carbon, water, energy, trace gases, and aerosols in Amazonia: The LBAEUSTACH experiments, J. Geophys. Res., 107(D20), 8066, doi:10.1029/2001JD000524, 2002.

Atkinson, R. and Arey, J.: Atmospheric chemistry of biogenic organic compounds, Acc. Chem. Res., 31, 574-583, 1998.

Bai, J., Baker, B., Liang, B., Greenberg, J., and Guenther, A.: Isoprene and monoterpene emissions from an Inner Mongolia grassland, Atmos. Environ., in press, 2006.

Baldocchi, D.: Flux footprints within and over forest canopies, Boundary-Layer Meteorology, 85(2), 273-292, 1997.

Bey, I., Jacob, D. J., Yantosca, R. M., Logan, J. A., Field, B. D., Fiore, A. M., Li, Q., Liu, H. Y., Mickley, L. J., and Schultz, 
M. G.: Global modeling of tropospheric chemistry with assimilated meteorology: Model description and evaluation, J. Geophys. Res., 106, 23 073-23 096, 2001.

Bonan, G. B., Levis, S., Kergoat, L., and Oleson, K. W.: Landscapes as patches of plant functional types: An integrating concept for climate and ecosystem models, Global Biogeochem. Cycles, 16(2), 1021, doi:10.1029/2000GB001360, 2002.

Brown, J. and Smith, J.: Wildland fire in ecosystems: effects of fire on flora, U.S. Department of Agriculture, Forest Service, Ogden, UT, 2000.

Bruggemann, N. and Schnitzler, J. P.: Diurnal variation of dimethylallyl diphosphate concentrations in oak (Quercus robur L.) leaves, Physiol. Plant., 115, 190-196, 2002.

Buckley, P. T.: Isoprene emissions from a Florida scrub oak species grown in ambient and elevated carbon dioxide, Atmos. Environ., 35, 631-634, 2001.

Centritto, M., Nascetti, P., Petrilli, L., Raschi, A., and Loreto, F.: Profiles of isoprene emission and photosynthetic parameters in hybrid poplars exposed to free-air $\mathrm{CO} 2$ enrichment, Plant Cell and Environment, 27(4), 403-412, 2004.

Che, H., Shi, G., Zhang, X., Arimoto, R., Zhao, J., Zhao, L., Wang, B., and Chen, Z.: Analysis of 40 years of solar radiation data from China, Geophys. Res. Lett., 32, L06803, doi:10.1029/2004GL022322, 2005.

Chen, F. and Dudhia, J.: Coupling an Advanced Land Surface Hydrology Model with the Penn State - NCAR MM5 Modeling System. Part I: Model Implementation and Sensitivity, Mon. Wea. Rev., 129(4), 569-585, 2001.

Clark, W.: China's Green Manure Revolution, Science, 80(1) 6973, 1980.

Collins, W. J., Derwent, R. G., Johnson, C. E., and Stevenson, D. S.: The oxidation of organic compounds in the troposphere and their global warming potentials, Climatic Change, 52(4), 28, 2002.

DeFries, R., Hansen, M., Townshend, J. R. G., Janetos, A. C., and Loveland, T. R.: A new global $1 \mathrm{~km}$ data set of percent tree cover derived from remote sensing, Global Change Biology, 6, 247254,2000

Dudhia, J. and Bresch, J. F.: A global version of the PSU-NCAR mesoscale model, Mon. Wea. Rev., 130, 2989-3007, 2002.

Ehhalt, D. and Prather, M.: Atmospheric Chemistry and Greenhouse Gases, in: Climate Change 2001; Working Group 1: The Scientific Basis, edited by: Houghton, J., Ding, Y., Griggs, D., Noguer, M., van der Linden, P., and Xiaosu, D., Cambridge University Press, 2001.

Ennis, C. A., Lazrus, A. L., Zimmerman, P. R., and Monson, R. K.: Flux determination and physiological response in exposure of red spruce to gaseous hydrogen peroxide, ozone, and sulfur dioxide., Tellus Series B - Chemical and Physical Meteorology, 42B, 183-199, 1990.

Fall, R. and Wildermuth, M. C.: Isoprene synthase: From biochemical mechanism to emission algorithm, J. Geophys. Res., 103(D19), 25, 1998.

Friedl, M. A., McIver, D. K., Hodges, J. C. F., Zhang, X. Y., Muchoney, D., Strahler, A. H., Woodcock, C. E., Gopal, S., Schneider, A., Cooper, A., Baccini, A., Gao, F., and Schaaf, C.: Global Land Cover Mapping from MODIS: Algorithms and Early Results, Remote Sens. Environ., 83(1-2), 287-302, 2002.

Fuentes, J. D., Lerdau, M., Atkinson, R., Baldocchi, D., Bottenheim, J. W., Ciccioli, P., Lamb, B., Geron, C., Gu, L., Guenther,
A., Sharkey, T. D., and Stockwell, W.: Biogenic Hydrocarbons in the Atmospheric Boundary Layer: A Review, Bull. Amer. Meteorol. Soc., 81(7), 1537-1576, 2000.

Fukui, Y. and Doskey, P. V.: Air-surface exchange of nonmethane organic compounds at a grassland site: Seasonal variations and stressed emissions, J. Geophys. Res., 103(D11), 13, 1998.

Funk, J. L., Jones, C. G., Baker, C. J., Fuller, H. M., Giardina, C. P., and Lerdau, M. T.: Diurnal variation in the basal emission rate of isoprene, Ecological Applications, 13(1), 269, 2003.

Geron, C. D., Guenther, A. B., and Pierce, T. E.: An improved model for estimating emissions of volatile organic compounds from forests in the eastern United States (Paper 94JD00246), J. Geophys. Res., 99(D6), 12 773, 1994.

Geron, C., Guenther, A., Sharkey, T., and Arnts, R. R.: Temporal variability in basal isoprene emission factor, Tree Physiology, 20(12), 799-805, 2000.

Geron, C., Owen, S., Guenther, A., Greenberg, J., Rasmussen, R., Bai, J. H., Li, Q. J., and Baker, B.: Volatile organic compounds from vegetation in southern Yunnan Province, China: Emission rates and some potential regional implications, Atmos. Environ., 40(10), 1759-1773, 2006.

Goldstein, A., Goulden, M., Munger, J. W., Wofsy, S., and Geron, C.: Seasonal course of isoprene emissions from a midlatitude forest, J. Geophys. Res., 103, 31 045-31 056, 1998.

Graedel, T. E., Bates, T. S., Bouwman, A. F., Cunnold, D., Dignon, J., Fung, I., Jacob, D. J., Lamb, B. K., Logan, J. A., Marland, G., Middleton, P., Pacyna, J. M., Placet, M., and Veldt, C.: A compilation of inventories of emissions to the atmosphere, Global Biogeochem. Cycles, 7, 1-26, 1993.

Granier, C., Petron, G., Muller, J. F., and Brasseur, G.: The impact of natural and anthropogenic hydrocarbons on the tropospheric budget of carbon monoxide, Atmos. Environ., 34(29-30), 52555270, 2000.

Greenberg, J. P., Guenther, A., Zimmerman, P., Baugh, W., Geron, C., Davis, K., Helmig, D., and Klinger, L. F.: Tethered balloon measurements of biogenic VOCs in the atmospheric boundary layer, Atmos. Environ., 33(6), 855-867, 1999.

Guenther, A. B., Monson, R. K., and Fall, R.: Isoprene and monoterpene emission rate variability: Observations with eucalyptus and Emission Rate Algorithm Development, J. Geophys. Res., 96, 10 799-10 808, 1991.

Guenther, A. B., Zimmerman, P. R., Harley, P. C., Monson, R. K., and Fall, R.: Isoprene and Monoterpene Emission Rate Variability - Model Evaluations and Sensitivity Analyses, J. Geophys. Res.-Atmos., 98(D7), 12 609-12 617, 1993.

Guenther, A., Hewitt, C. N., Erickson, D., Fall, R., Geron, C., Graedel, T., Harley, P., Klinger, L., Lerdau, M., Mckay, W. A., Pierce, T., Scholes, B., Steinbrecher, R., Tallamraju, R., Taylor, J., and Zimmerman, P. A.: Global-Model of Natural Volatile Organic-Compound Emissions, J. Geophys. Res.Atmos., 100(D5), 8873-8892, 1995.

Guenther, A., Greenberg, J., Harley, P., Helmig, D., Klinger, L., Vierling, L., Zimmerman, P., and Geron, C.: Leaf, branch, stand and landscape scale measurements of volatile organic compound fluxes from US woodlands, Tree Physiology, 16(1-2), 17-24, 1996.

Guenther, A., Baugh, B., Brasseur, G., Greenberg, J., Harley, P., Klinger, L., Serca, D., and Vierling, L.: Isoprene emission estimates and uncertainties for the Central African EXPRESSO 
study domain, J. Geophys. Res.-Atmos., 104(D23), $30625-$ 30 639, 1999a.

Guenther, A., Archer, S., Greenberg, J., Harley, P., Helmig, D., Klinger, L., Vierling, L., Wildermuth, M., Zimmerman, P., and Zitzer, S.: Biogenic hydrocarbon emissions and landcover/climate change in a subtropical savanna, Phys. Chem. Earth Part B - Hydrology Oceans and Atmosphere, 24(6), 659$667,1999 b$.

Guenther, A., Geron, C., Pierce, T., Lamb, B., Harley, P., and Fall, R.: Natural emissions of non-methane volatile organic compounds; carbon monoxide, and oxides of nitrogen from North America, Atmos. Environ., 34(12-14), 2205-2230, 2000.

Guenther, A. B. and Hills, A. J.: Eddy covariance measurement of isoprene fluxes, J. Geophys. Res., 103(D11), 13, 1998.

Guenther, A.: The contribution of reactive carbon emissions from vegetation to the carbon balance of terrestrial ecosystems, Chemosphere, 49(8), 837-844, 2002.

Hansen, M., DeFries, R., Townshend, J. R. G., and Sohlberg, R.: Global land cover classification at $1 \mathrm{~km}$ resolution using a decision tree classifier, Int. J. Remote Sens., 21, 1331-1365, 2000.

Hansen, M., DeFries, R. S., Townshend, J. R. G., Carroll, M., Dimiceli, C., and Sohlberg, R. A.: Global Percent Tree Cover at a Spatial Resolution of 500 Meters: First Results of the MODIS Vegetation Continuous Fields Algorithm” Earth Interactions, 7(10), 1-15, 2003.

Hanson, D. T. and Sharkey, T. D.: Rate of acclimation of the capacity for isoprene emission in response to light and temperature, Plant, Cell \& Environment, 24(9), 937-946, 2001.

Harley, P. C., Litvak, M. E., Sharkey, T. D., and Monson, R. K.: Isoprene Emission from Velvet Bean-Leaves - Interactions among Nitrogen Availability, Growth Photon Flux-Density, and Leaf Development, Plant Physiology, 105(1), 279-285, 1994.

Harley, P., Vasconcellos, P., Vierling, L., Pinheiro, C., Greenberg, J., Guenther, A., Klinger, L., Almeida, S., Neill, D., Baker, T., Phillips, O., and Malhi, Y.: Variation in potential for isoprene emissions among Neotropical forest sites, Global Change Biology, 10, 630-650, 2004.

Houweling, S., Dentener, F., and Lelieveld, J.: The impact of nonmethane hydrocarbon compounds on tropospheric photochemistry, J. Geophys. Res., 103, 10 673-10 696, 1998.

Isebrands, J. G., Guenther, A. B., Harley, P., Helmig, D., Klinger, L., Vierling, L., Zimmerman, P., and Geron, C.: Volatile organic compound emission rates from mixed deciduous and coniferous forests in Northern Wisconsin, USA, Atmos. Environ., 33(16), 2527-2536, 1999.

Isidorov, V.: Organic Chemistry of the Earth's Atmosphere, Springer-Verlag, Berlin, 1990.

Janson, R., De Serves, C., and Romero, R.: Emission of isoprene and carbonyl compounds from a boreal forest and wetland in Sweden, Agric. For. Meteorol., 98-9, 671-681, 1999.

Kanamitsu, M., Ebisuzaki, W., Woollen, J., Yang, S. K., Hnilo, J. J., Fiorino, M., and Potter, G. L.: NCEP-DOE AMIP-II reanalysis (R-2), Bull. Amer. Meteorol. Soc., 83(11), 1631-1643, 2002.

Karl, T., Guenther, A., Spirig, C., Hansel, A., and Fall, R.: Seasonal variation of biogenic VOC emissions above a mixed hardwood forest in northern Michigan, Geophys. Res. Lett., 30(23), 2186, 2003.

Karl, T., Potosnak, M., Guenther, A., Clark, D., Walker, J., Herrick, J. D., and Geron, C.: Exchange processes of volatile organic compounds above a tropical rain forest: Implications for modeling tropospheric chemistry above dense vegetation, J. Geophys. Res.-Atmos., 109(D18), D18306, doi:10.1029/2004JD004738, 2004.

Keller, M. and Lerdau, M.: Isoprene emission from tropical forest canopy leaves, Global Biogeochem. Cycles, 13, 19-29, 1999.

Kesselmeier, J., Kuhn, U., Wolf, A., Andreae, M. O., Ciccioli, P., Brancaleoni, E., Frattoni, M., Guenther, A., Greenberg, J., Vasconcellos, P. D., de Oliva, T., Tavares, T., and Artaxo, P.: Atmospheric volatile organic compounds (VOC) at a remote tropical forest site in central Amazonia, Atmos. Environ., 34(24), 40634072, 2000.

Keppler, F., Hamilton, J. T. G., Braß, M., and Röckmann, T.: Methane emissions from terrestrial plants under aerobic conditions, Nature, 439, 187-191, doi:10.1038/nature04420, 2006.

Kinnee, E., Geron, C., and Pierce, T.: United States land use inventory for estimating biogenic ozone precursor emissions, Ecological Applications, 7(1), 46-58, 1997.

Kirstine, W., Galbally, I., Ye, Y., and Hooper, M.: Emissions of volatile organic compounds (primarily oxygenated species) from pasture, J. Geophys. Res., 103(D9), 10, 1998.

Klein Goldewijk, K.: Estimating global land use change over the past 300 years: The HYDE database, Global Biogeochem. Cycles, 15(2), 417-433, 2001.

Klinger, L., Zimmerman, P., Greenberg, J., Heidt, L., and Guenther, A.: Carbon trace gas fluxes along a successional gradient in the Hudson Bay lowland, J. Geophys. Res., 99, 1469-1494, 1994.

Klinger, L. F., Li, Q. J., Guenther, A. B., Greenberg, J. P., Baker, B., and Bai, J. H.: Assessment of volatile organic compound emissions from ecosystems of China, J. Geophys. Res., 107(D21), 4603, doi:10.1029/2001JD001076, 2002.

Kuhn, U., Rottenberger, S., Biesenthal, T., Wolf, A., Schebeske, G., Ciccioli, P., Brancaleoni, E., Frattoni, M., Tavares, T. M., and Kesselmeier, J.: Isoprene and monoterpene emissions of Amazonian tree species during the wet season: Direct and indirect investigations on controlling environmental functions, J. Geophys. Res.-Atmos., 107, 8071, 2002.

Lamb, B., Allwine, E., Dilts, S., Westberg, H., Pierce, T., Geron, C., Baldocchi, D., Guenther, A., Klinger, L., Harley, P., and Zimmerman, P.: Evaluation of forest canopy models for estimating isoprene emissions, J. Geophys. Res., 101, 22 787-22 798, 1996.

Leemans, R. and Cramer, W.: IIASA database for mean monthly values of temperature, precipitation, and cloudiness on a global terrestrial grid: Digital raster data on a 30 minute geographic (lat/long) 320 times 720 grid, in: Global ecosystems Database Version 1.0: Disc A, NOAA National Geophyscial Data Center, Boulder, CO, 1992.

Leff, B., Ramankutty, N., and Foley, J. A.: Geographic distribution of major crops across the world, Global Biogeochem. Cycles, 18, GB1009, doi:10.1029/2003GB002108, 2004.

Liepert, B. G.: Observed reductions of surface solar radiation at sites in the United States and worldwide from 1961 to 1990, Geophys. Res. Lett., 29(10), doi:10.1029/2002GLO14910, 2002.

Makar, P., Fuentes, J., Wang, D., Staebler, R., and Wiebe, H.: Chemical processing of biogenic hydrocarbons within and above a temperate deciduous forest, J. Geophys. Res., 104(D3), 35813603, 1999.

Martin, P. H. and Guenther, A. B.: Insights into the dynamics of forest succession and non-methane hydrocarbon trace gas emis- 
sions, J. Biogeography, 22, 493-499, 1995.

Martin, R. V., Parrish, D. D., Ryerson, T. B., Nicks Jr., D. K., Chance, K., Kurosu, T. P., Fried, A., Wert, B. P., Jacob, D. J., and Sturges, E. D.: Evaluation of GOME satellite measurements of tropospheric $\mathrm{NO}_{2}$ and $\mathrm{HCHO}$ using regional data from aircraft campaigns in the southeastern United States, J. Geophys. Res., 109, D24307, doi:10.1029/2004JD004869, 2004.

Monson, R., Harley, P., Litvak, M., Wildermuth, M., Guenther, A., Zimmerman, P., and Fall, R.: Environmental and developmental controls over the seasonal pattern of isoprene emission from aspen leaves, Oecologia, 99, 260-270, 1994.

Muller, J. F.: Geographical-Distribution and Seasonal-Variation of Surface Emissions and Deposition Velocities of Atmospheric Trace Gases, J. Geophys. Res.-Atmos., 97(D4), 3787-3804, 1992.

Myneni, R. B., Nemani, R. R., and Running S. W.: Estimation of global leaf area index and absorped par using radiative transfer models, IEEE Trans. Geosci. Rem. Sens., 35, 1380-1393, 1997.

Neilson, R. P.: A model for predicting continental-scale vegetation distribution and water balance, Ecological Applications, 5, 362$385,1995$.

Olson, J.: World ecosystems (WE1.4): Digital raster data on a 10 minute geographic $1080 \times 2160$ grid, Global Ecosytems Database, Version 1.0: Disc A., N. G. D. Center, Boulder CO, Nat. Ocean. Atmos. Admin., 1992.

Olson, D. M., Dinerstein, E., Wikramanayake, E. D., Burgess, N. D., Powell, G. V. N., Underwood, E. C., D’ Amico, J. A., Itoua, I., Strand, H. E., Morrison, J. C., Loucks, C. J., Allnutt, T. F., Ricketts, T. H., Kura, Y., Lamoreux, J. F., Wettengel, W. W., Hedao, P., and Kassem, K. R.: Terrestrial Ecoregions of the World: A New Map of Life on Earth., BioScience, 51(11), 933-938, 2001.

Otter, L., Guenther, A., Wiedinmyer, C., Fleming, G., Harley, P., and Greenberg, J.: Spatial and temporal variations in biogenic volatile organic compound emissions for Africa south of the equator, J. Geophys. Res., 108(13), doi:10.1029/2002JD002609, 2003.

Palmer, P. I., Jacob, D. J., Chance, K., Martin, R. V., Spurr, R. J. D., Kurosu, T. P., Bey, I., Yantosca, R., Fiore, A., and Li, Q. B.: Air mass factor formulation for spectroscopic measurements from satellites: Application to formaldehyde retrievals from the Global Ozone Monitoring Experiment, J. Geophys. Res., 106, 14 539-14 550, 2001.

Palmer, P. I., Jacob, D. J., Fiore, A. M., Martin, R. V., Chance, K., and Kurosu, T. P.: Mapping isoprene emissions over North America using formaldehyde column observations from space, J. Geophys. Res., 108(D6), 4180, doi:10.1029/2002JD002153, 2003.

Palmer, P., Abbot, D., Fu, T.-M., Jacob, D., Chance, K., Kurosu, T., Guenther, A., Wiedinmyer, C., Stanton, J., Pilling, M., Pressley, S., Lamb, B., and Sumner, A.: Quantifying the seasonal and interannual variability of North American isoprene emissions using satellite observations of formaldehyde column, J. Geophys. Res., in press, 2006.

Pegoraro, E., Rey, A., Bobich, E., Barron-Gafford, G., Grieve, A., Malhi, Y., and Murthy, R.: Effect of $\mathrm{CO} 2$ concentration and vapour pressure deficit on isoprene emission from leaves of Populus deltoides during drought, Functional Plant Biology, 31(12), 1137-1147, 2004.

Petron, G., Harley, P., Greenberg, J., and Guenther, A.: Seasonal temperature variations influence isoprene emission, Geophys. Res. Lett., 28 (9), 1707-1710, 2001.

Pierce, T. E. and Waldruff, P. S.: Pc-Beis - a Personal-Computer Version of the Biogenic Emissions Inventory System, J. Air Waste Manage. Assoc., 41(7), 937-941, 1991.

Pierce, T., Geron, C., Bender, L., Dennis, R., Tonnesen, G., and Guenther, A.: Influence of increased isoprene emissions on regional ozone modeling, J. Geophys. Res.-Atmos., 103(D19), 25 611-25 629, 1998.

Poisson, N., Kanakidou, M., and Crutzen, P. J.: Impact of nonmethane hydrocarbons on tropospheric chemistry and the oxidizing power of the global troposphere: 3-dimensional modelling results, J. Atmos. Chem., 36, 157-230, 2000.

Ramankutty, N. and Foley, J. A.: Estimating historical changes in land cover: North American croplands from 1850 to 1992, Global Ecology and Biogeography, 8, 381-396, 1999.

Rapparini, F., Baraldi, R., Miglietta, F., and Loreto, F.: Isoprenoid emission in trees of Quercus pubescens and Quercus ilex with lifetime exposure to naturally high $\mathrm{CO} 2$ environment, Plant, Cell and Environment, 27, 381-391, 2004.

Rasmussen, R. and Went, F.: Volatile organic material of plant origin in the atmosphere, Proc. Natl. Acad. Sci., 53, 215-220, 1965.

Rosenstiel, T. N., Potosnak, M. J., Griffin, K. L., Fall, R., and Monson, R. K.: Increased CO2 uncouples growth from isoprene emission in an agriforest ecosystem, Nature, 421, 256-259, 2003.

Sanadze, G.: The nature of gaseous substances emitted by leaves of Robinia pseudoacacia, Soobshch. Akad. Nauk Gruz. SSR, 27, 747-750, 1957.

Sanderson, M. G., Jones, C. D., Collins, W. J., Johnson, C. E., and Derwent, R. G.: Effect of climate change on isoprene emissions and surface ozone levels, Geophys. Res. Lett., 30(18), 1936, 2003.

Schaab, G., Steinbrecher, R., Lacaze, B., and Lenz, R.: Assessment of long-term vegetation changes on potential isoprenoid emission for a Mediterranean-type ecosystem in France, J. Geophys. Res.Atmos., 105(D23), 28 863-28 873, 2000.

Sharkey, T. D., Singsaas, E. L., Lerdau, M. T., and Geron, C.: Weather effects on isoprene emission capacity and applications in emissions algorithms, Ecol. Appl., 9, 1132-1137, 2000.

Shim, C., Wang, Y., Choi, Y., Palmer, P., Abbot, D., Chance, K.: Constraining global isoprene emissions with Global Ozone Monitoring Experiment (GOME) formaldehyde column measurements, J. Geophys. Res., 110, D24301, doi:10.1029/2004JD005629, 2005.

Silver, G. M. and Fall, R.: Characterization of Aspen Isoprene Synthase, an Enzyme Responsible for Leaf Isoprene Emission to the Atmosphere, J. Biological Chemistry, 270(22), 13 010-13 016, 1995.

Simpson, D., Winiwarter, W., Borjesson, G., Cinderby, S., Ferreiro, A., Guenther, A., Hewitt, C. N., Janson, R., Khalil, M. A. K., Owen, S., Pierce, T. E., Puxbaum, H., Shearer, M., Skiba, U., Steinbrecher, R., Tarrason, L., and Oquist, M. G.: Inventorying emissions from nature in Europe, J. Geophys. Res.-Atmos., 104(D7), 8113-8152, 1999.

Strong, C., Fuentes, J. D., and Baldocchi, D.: Reactive hydrocarbon flux footprints during canopy senescence, Agric. For. Meteorol., 127(3-4), 159-173, 2004.

Stroud, C., Makar, P., Karl, T., Guenther, A., Geron, C., Turnipseed, A., Nemitz, E., Baker, B., Potosnak, M., and Fuentes, J.: 
Role of Canopy-Scale Photochemistry in Modifying BiogenicAtmosphere Exchange of Reactive Terpene Species: Results from the CELTIC Field Study, J. Geophys. Res., 110, D17303, doi:10.1029/2005JD005775, 2005.

Tian, Y., Dickinson, R. E., Zhou, L., Myneni, R. B., Friedl, M., Schaaf, C. B., Carroll, M., and Gao, F.: Land boundary conditions from MODIS data and consequences for the albedo of a climate model, Geophys. Res. Lett., 31(5), L05504, doi:1029/2003GL019104, 2004.

Trostdorf, C., Gatti, L., Yamazaki, A., Martins, W., Potosnak, M., Guenther, A., Martins, W., and Munger, J.: Seasonal cycles of isoprene concentrations in the Amazonian rainforest, Atmos. Chem. Phys. Discuss., 4, 1291-1310, 2004, http://www.atmos-chem-phys-discuss.net/4/1291/2004/.

Turner, D. P., Baglio, J. V., Wones, A. G., Pross, D., Vong, R., Mcveety, B. D., and Phillips, D. L.: Climate change and Isoprene emissions from vegetation, Chemosphere, 23, 37-56, 1991.

Velikova, V., Pinelli, P., Pasqualini, S., Reale, L., Ferranti, F., and Loreto, F.: Isoprene decreases the concentration of nitric oxide in leaves exposed to elevated ozone, New Phytologist, 166(2), 419-426, 2005.

Wagner, W., Nemecek-Marshall M., and Fall, R.: Three Distinct Phases of Isoprene Formation during Growth and Sporulation of Bacillus subtilis, J. Bacteriology, 181(15), 4700-4703, 1999.

Wang, Y. and Jacob, D. J.: Anthropogenic forcing on tropospheric ozone and $\mathrm{OH}$ since preindustrial times, J. Geophys. Res., 103, 31 123-31 135, 1998.

Went, F. W.: Blue hazes in the atmosphere, Nature, 187(4738), 641643, 1960.
Wert, B. P., Trainer, M., Fried, A., Ryerson, T. B., Henry, B., Potter, W., Angevine, W. M., Atlas, E., Donnelly, S. G., Fehsenfeld, F. C., Frost, G. J., Goldan, P. D., Hansel, A., Holloway, J. S., Hubler, G., Kuster, W. C., Nicks, D. K., Neuman, J. A., Parrish, D. D., Schauffler, S., Stutz, J., Sueper, D. T., Wiedinmyer, C., and Wisthaler, A.: Signatures of terminal alkene oxidation in airborne formaldehyde measurement during TexAQS 2000, J. Geophys. Res., 108(D3), 4104, doi:10.1029/2002JD002502, 2003.

Wiedinmyer, C., Guenther, A., Harley, P., Hewitt, C. N., Geron, C., Artaxo, P., Steinbrecher, R., and Rasmussen, R.: Global organic emissions from vegetation, in: Emissions of Atmospheric Trace Compounds, edited by: Granier, C., Kluwer Publishing Co., Dordrecht, The Netherlands, 2004.

Wiedinmyer, C., Tie, X., Guenther, A., Neilson,, R., and Granier, C.: Future Changes in Biogenic Isoprene Emissions: How Might They Affect Regional and Global Atmospheric Chemistry?, Earth Interact., 10(3), EI174, doi:10.1175/EI174.1, 2006.

Wolfertz, M., Sharkey, T. D., Boland, W., Kuhnemann, F., Yeh, S., and Weise, S. E.: Biochemical regulation of isoprene emission, Plant Cell and Environment, 26(8), 1357-1364, 2003.

Zeng, X.: Global Vegetation Root Distribution for Land Modeling, J. Hydrometeorol., 2(5), 525-530, 2001.

Zhang, P. Anderson, B., Barlow, M., Tan, B., and Myneni, R.: Climate related vegetation characteristics derived from MODIS LAI and NDVI, J. Geophys. Res., 109, D20105, doi:10.1029/2004JD004720, 2004.

Zimmerman, P.: Testing of hydrocarbon emissions from vegetation, leaf litter and aquatic surfaces and development of a method for compiling biogenic emission inventories, EPA-450-4-70-004, U.S. Environmental Protection Agency, Research Triangle Park, NC, 1979. 